\title{
Ultrasound characteristics of endometrial cancer as defined by the International Endometrial Tumor Analysis (IETA) consensus nomenclature - A prospective multicenter study
}

Elisabeth Epstein ${ }^{1}$, Daniela Fischerova ${ }^{2}$, Lil Valentin ${ }^{3}$, Antonia Carla Testa ${ }^{4}$, Dorella Franchi ${ }^{5}$, Povilas Sladkevicius ${ }^{3}$, Filip Frühauf ${ }^{2}$, Pelle G Lindqvist ${ }^{6}$, Floriana Mascilini ${ }^{4}$, Robert Fruscio ${ }^{7}$, Lucia Anna Haak ${ }^{8}$, Gina Opolskiene ${ }^{9}$, Maria Angela Pascual ${ }^{10}$, Juan Luis Alcazar ${ }^{11}$, Valentina Chiappa $^{12}$, Stefano Guerriero ${ }^{13}$, Joseph Carlson ${ }^{14}$, Caroline Van Holsbeke ${ }^{15}$, Francesco Paolo Giuseppe Leone ${ }^{16}$, Bart De Moor ${ }^{17}$, Tom Bourne ${ }^{18,19}$, Ben van Calster ${ }^{19}$, Arnaud Installe ${ }^{17}$, Dirk Timmerman ${ }^{19,20}$, Jan Y Verbakel ${ }^{19,}$ 21, Thierry Van den Bosch ${ }^{20}$

${ }^{1}$ Department of Clinical Science and Education, Södersjukhuset and Department of Women's and Children's health Karolinska Institutet, Stockholm, Sweden

2Department of Obstetrics and Gynecology, First Faculty of Medicine, Charles University, Prague, Czech Republic

32Department of Obstetrics and Gynecology, Skåne University Hospital, Malmö, Lund University, Sweden

${ }^{4}$ Department of Gynecological Oncology, Catholic University of Sacred Heart, Rome, Italy

5Department of Gynecological Oncology, Milan, Italy

6Department of Obstetrics and Gynecology, Karolinska University Hospital Huddinge, Stockholm, Sweden

${ }^{7}$ Clinic of Obstetrics and Gynecology, University of Milan Bicocca, San Gerardo Hospital, Monza, Italy

${ }^{8}$ Institute for the Care of Mother and Child, Prague, Czech Republic and Third Faculty of

Medicine, Charles University, Prague, Czech Republic

${ }^{9}$ Center of Obstetrics and Gynecology, Vilnius University Hospital, Santariskiu clinic, Lithuania

${ }^{10}$ Department of Obstetrics, Gynecology, and Reproduction, Hospital Universitario Dexeus,

Barcelona, Spain.

${ }^{11}$ Department of Obstetrics and Gynecology, Clinica Universidad de Navarra, Pamplona, Spain

${ }^{12}$ Department of Obstetrics and Gynecology, National Cancer Institute, Milan, Italy

${ }^{13}$ Department of Obstetrics and Gynecology, University of Cagliari, Policlinico Universitario

Duilio Casula, Monserrato, Cagliari, Italy

${ }^{14}$ Department of Pathology, Karolinska University Hospital, Stockholm, Sweden

${ }^{15}$ Department of Obstetrics and Gynecology, Ziekenhuis Oost-Limburg, Genk, Belgium

16Department of Obstetrics and Gynecology, Clinical Sciences Institute, L. Sacco, Milan, Italy

${ }^{17}$ Department of Electrical Engineering, ESAT-SCD, STADIUS Center for Dynamical Systems,

Signal Processing and Data Analysis, KU Leuven, and imec, Leuven Belgium

${ }^{18}$ Department of Obstetrics and Gynaecology, Queen Charlottes and Chelsea Hospital, Imperial

College London, UK

${ }^{19}$ Department of Development and Regeneration, KU Leuven, Leuven, Belgium

${ }^{20}$ Department of Obstetrics and Gynecology, University Hospital Leuven, Leuven, Belgium

${ }^{21}$ Nuffield Department of Primary Care Health Sciences, University of Oxford, UK

Keywords: ultrasonography, ultrasonography Doppler, endometrial neoplasm,

diagnostic imaging, neoplasm staging

Short title: Ultrasound characteristics of endometrial cancer

This article has been accepted for publication and undergone full peer review but has not been through the copyediting, typesetting, pagination and proofreading process, which may lead to differences between this version and the Version of Record. Please cite this article as doi: 10.1002/uog.18909 
Corresponding author: Elisabeth Epstein, MD, PhD, Department of Obstetrics and Gynecology, Södersjukhuset, Sjukhusbacken 10,11883 Stockholm, Sweden, E-Mail: elisabeth.epstein@sll.se

\begin{abstract}
:
Objectives: To describe the sonographic features of endometrial cancer in relation to stage, grade, and histological type using the International Endometrial Tumor Analysis (IETA) terminology.
\end{abstract}

Methods: Prospective multicenter study on 1714 women with endometrial cancer undergoing a standardized transvaginal grayscale and Doppler ultrasound examination by an experienced ultrasound examiner using a high-end ultrasound system. Clinical and sonographic data were entered into a web-based protocol. We assessed how strongly sonographic characteristics, according to IETA, were associated to outcome at hysterectomy, i.e. tumor stage, grade, and histological type.

Results: After excluding 176 women (no or delayed hysterectomy, final diagnosis other than endometrial cancer, or incomplete data), 1538 women were included in our statistical analysis. Median age was 65 years (range 27-98), and median BMI 28.4 (range 16-67), 1378 (89.7\%) women were postmenopausal, and 1296 (84.2\%) reported abnormal vaginal bleeding. Grayscale and color Doppler features varied according to grade and stage. High-risk tumors (stage $1 \mathrm{~A}$, grade 3 or non-endometrioid or $\geq$ stage $1 \mathrm{~B}$ ) were less likely to have regular endometrial myometrial border (difference of $-23 \%$, 95\% CI -27 to -18\%), whilst they were larger (mean endometrial thickness; difference of $+9 \mathrm{~mm}, 95 \% \mathrm{CI}+8$ to $+11 \mathrm{~mm}$ ), more frequently had non-uniform echogenicity (difference of $+10 \%, 95 \% \mathrm{CI}+5$ to $+15 \%$ ), a multiple, multifocal vessel pattern (difference of $+21 \%, 95 \%$ CI +16 to $+26 \%$ ), and a moderate or high color score (difference of $+22 \%, 95 \% \mathrm{CI}+18$ to $+27 \%$ ), than low-risk tumors. 
Conclusion: Grayscale and color Doppler ultrasound features are associated with grade and stage, and differ between high and low risk endometrial cancer.

\section{Introduction}

Endometrial cancer is the most common malignancy of the female genital tract in developed countries with a cumulative risk of $1.8 \% .^{1}$ The number of newly diagnosed cases in Europe was above 100,000 in 2012, with an age standardized incidence of 14.7 per 100,000 women per year. ${ }^{1}$ Prognosis depends on the patient's age, histological type of malignancy, tumor grade, lymphovascular space invasion, tumor size, depth of myometrial invasion, cervical stromal invasion, and tumor involvement of the lower uterine segment. $^{2-4}$ The prognosis is excellent in most women with stage I disease (96\% 5-year survival). The prognosis is worse for women with high-risk disease (grade 3 or non-endometrioid histotype and/or stage $\geq 1 \mathrm{~B}$ ), because these women are at increased risk of lymph node metastasis, distant tumor spread and tumor recurrence. ${ }^{5}$ Physicians need to identify high-risk patients preoperatively to tailor treatment and achieve optimal long-term survival.

Tumor size, depth of myometrial invasion and cervical stromal involvement cannot be determined by clinical examination. Therefore, ultrasound and magnetic resonance imaging (MRI) are being increasingly used to improve preoperative evaluation, i.e. to identify women in need of more extensive surgery including pelvic- and para-aortic lymph node dissection. ${ }^{6-8}$ According to the European Societies of Gynecological Oncology, for Medical Oncology, and Radiotherapy and Oncology (ESGO/ESMO/ESTRO) the preoperative work-up should include pelvic examination, transvaginal or transrectal ultrasonography, and pathology assessment of an endometrial biopsy (histological type 
and grade)..$^{5}$ To optimize the sonographic assessment of endometrial tumors a better understanding of the association between sonographic features and stage, grade, and histological type is needed.

The aim of this study is to describe the sonographic features of endometrial cancer in relation to histological type, tumor grade and stage when using the International Endometrial Tumor Analysis (IETA) ${ }^{9}$ examination technique and terminology.

\section{Methods}

This prospective cross-sectional multicenter-study included women with biopsy confirmed endometrial cancer examined using transvaginal ultrasound according to the IETA study protocol. Patients were recruited between January $1^{\text {st }} 2011$ and December $31^{\text {st }} 2015$ from 17 European ultrasound centers (Supplementary Table 1). We aimed at including consecutive women to avoid selection bias, and to achieve at least 1500 inclusions to be able to make sub-analyses on non-endometrioid histological types and on premenopausal women. Exclusion criteria were hysterectomy not performed or performed $>120$ days after the ultrasound examination, final diagnosis other than endometrial cancer, tumor duplicity (i.e. other synchronous gynecological malignancy), incomplete ultrasound information, and loss to follow-up.

The research protocol was approved by the local Ethics Committee/ Review Board at each center. Hysterectomy and bilateral salpingo-oophorectomy was performed through laparotomy, vaginally, or via minimally invasive techniques such as laparoscopy or robotic surgery. Systematic pelvic and para-aortic lymphadenectomy was performed to stage high-risk tumors according to local protocols. We used the International 
Federation of Gynecology and Obstetrics (FIGO) 2009 staging criteria based on surgical findings at hysterectomy. ${ }^{4}$

The ultrasound examinations were performed by the affiliated investigators at each center (Supplementary Figure 1) using the standardized examination and measurement technique described in the IETA consensus statement ${ }^{9}$. All ultrasound examiners were gynecologists with extensive experience in gynecological ultrasound, and all used highend ultrasound equipment. The ultrasound systems used in this study were; GE Voluson E8, GE Voluson E10, GE Voluson 730, GE Voluson S8, Samsung Elite, Siemens S2000, Philips EPIQ, Philips IU22, Medison Sonoace R3, Mindray, Sequoia 512, Esaote My Lab, Antares R5, Antares 2000.

The women were examined in the lithotomy position with an empty bladder. The uterus was scanned in the sagittal plane from cornu to cornu and in the transverse plane from the cervix to the fundus. The presence of adenomyosis and fibroids was noted. The following measurements were taken: anteroposterior diameter of the uterus and endometrium (endometrial thickness) in the sagittal plane, and latero-lateral diameter of the uterus (uterine width) in the transverse plane. In the presence of endometrial tumor, its three orthogonal diameters (antero-posterior [tumor thickness] and craniocaudal [tumor length] diameters in the sagittal plane, latero-lateral diameter [tumor width] in the transverse plane) were measured, as well as minimal tumor free margin and the distance from outer cervical os to the lowest margin of the tumor (Figure 1a-d). The minimal tumor-free margin was measured in any plane where the distance from the tumor to the serosa appeared to be at its smallest. Tumor volume was calculated using the three orthogonal tumor diameters, using the approximate formula for an ellipsoid $(\mathrm{D} 1 \mathrm{xD} 2 \mathrm{xD} 3) / 2$. 
Having established an overview of the whole uterus, the ultrasound image was magnified to comprise only the uterine corpus. The magnified image was used when describing the endometrial grayscale ultrasound morphology and vascularization using color/power Doppler according to IETA ${ }^{9}$ terms and definitions (Supplementary Figure 1). Color/Power Doppler examinations were carried out at Pulse Repetition Frequency (PRF) 0.3 to $0.9 \mathrm{kHz}$, with the gain and PRF adjusted so that vessels were clearly defined without "blooming".

The research protocol contained questions regarding each patient's medical, reproductive and vaginal bleeding history, demographic and biometric variables as well as sonographic variables. Data were entered into an internet-based electronic data capture software (Clinical Data Miner (https://cdm.esat.kuleuven.be) ${ }^{10}$ that included pictograms of all IETA ultrasound variables. Examiners were encouraged to enter and save ultrasound data on the day of the ultrasound examination. Incomplete data could not be saved. Once the data had been saved, they were locked and no changes could be made. Results regarding histology and tumor stage were entered following hysterectomy. In all centers a pathologist with substantial experience in gynecologic oncology assessed the pathological specimens. The histopathological variables assessed were histological type, grade of differentiation, and pathological stage. Only epithelial malignant tumors, i.e. endometrial carcinomas (endometrioid adenocarcinoma, mucinous adenocarcinoma, serous carcinoma, clear cell carcinoma, mixed cell carcinoma, undifferentiated carcinoma), and mixed epithelial and mesenchymal malignant tumors, i.e. carcinosarcomas were included. ${ }^{11}$ Endometrioid adenocarcinoma was classified into 3 grades (grade 1 = well differentiated, grade 2 = moderately 
differentiated, grade 3 = poorly differentiated). ${ }^{13}$ Low-risk endometrial cancer was defined as stage $1 \mathrm{~A}$, grade 1-2. High-risk endometrial cancer was divided into three groups to give us the possibility to investigate if there was any association between ultrasound features and stage, grade or histological type; A/ stage 1A grade 3 or nonendometroid histotype, $\mathrm{B} /$ stage $\geq 1 \mathrm{~B}$ grade 1 or $2, \mathrm{C} /$ stage $\geq 1 \mathrm{~B}$ grade 3 or nonendometrioid cancer.

To assess the ability of an ultrasound variable to discriminate low from high-risk cancer, and high tumor grade from low (grade 3 versus grade 1/2) we fitted a univariable logistic regression model and calculated the c-statistic (equivalent to the area under the Receiver-Operating-Characteristics, ROC curve) with its 95\% confidence interval. ${ }^{12}$ 95\% CIs for the difference in percentages were calculated using a Wilson score based method without continuity correction. ${ }^{13}$ 95\% CIs for the difference in medians were based on the percentile method using 1000 stratified bootstrap samples. The value of the c-statistic represents the probability to correctly distinguish between patients with or without the outcome of interest based on the value of the ultrasound variable. A c-statistic of 0.5 indicates no predictive ability, whereas a c-statistic of 1 indicates perfect discriminative ability. All statistical analyses were performed using $\mathrm{R}$ 3.2.4, (https://www.r-project.org/). 
Results

A total of 1714 women were recruited into the study. Of these, 176 women were excluded leaving 1538 women for final analysis. In 118 women hysterectomy was either not performed (due to co-morbidities), or surgery was carried out at another hospital so that data could not be retrieved, or hysterectomy was performed more than 120 days after the ultrasound examination. Twenty-five women had final diagnosis other than endometrial cancer or uterine carcinosarcoma: cervical cancer $(n=4)$, synchronous ovarian cancer $(n=3)$, synchronous tubal cancer $(n=2)$, endometrial stromal sarcoma $(n=8)$, adenosarcoma $(n=2)$, leiomyosarcoma $(n=4)$, Uterine Tumor Resembling Ovarian Sex Cord Tumor (UTROSCT) $(n=1)$, PEComa $(n=1)$. In 26 cases endometrial morphology assessment was not complete because some examiners did not correctly fill out the Study Protocol. Seven women were excluded due to duplicate entries $(n=5)$ or mistake in the identification key so that the patient could not be identified $(n=2)$.

The demographic background data and the histological outcome are shown in Table 1. Ninety percent (range between centers $80 \%$ to100\%) of the women were postmenopausal, $84 \%$ (range between centers $69 \%$ to $95 \%$ ) reported abnormal uterine bleeding, and $12 \%$ (range between centers $0 \%$ to $26 \%$ ) used systemic hormone replacement therapy or vaginal estrogens (estriol or estradiol). Sixty-one percent of tumors were stage $1 \mathrm{~A}$ (range between centers 49 to $87 \%$ ) and $86 \%$ of tumors were endometrioid (range between centers 71 to $100 \%$ ).

Table 2 shows the sonographic characteristics in relation to grade in endometrioid tumors and in non-endometrioid tumors. The higher the grade of endometrioid cancer, the thicker the endometrium, the higher the tumor volume, the lower the proportion of tumors with regular endometrial-myometrial border, and of tumors with uniform 
echogenicity, and the higher the proportion of tumors with multiple vessels of focal or multifocal origin and the higher the color score. The strongest discriminators between high and low grade cancer were greater tumor size (endometrial thickness and volume), non-regular endometrial/myometrial border, and high color score. Non-endometrioid tumors had vascularity similar to grade 3 endometrioid tumors but grayscale morphology similar to grade 1-2 endometrioid tumors.

Supplementary table 2 , show selected sonographic characteristics for endometrioid tumors in relation to grade $(1,2,3)$ and stage $(1 \mathrm{~A}$ or $\geq 1 \mathrm{~B})$. Irrespective of stage, the higher the grade the larger the tumor, the more common is non-uniform endometrial morphology and heterogeneous endometrium without cysts, and the less common is regular endometrial-myometrial junction, and no detectable vascularization. At the same time irrespective of grade, stage $\geq 1 \mathrm{~B}$ tumors are larger than stage $1 \mathrm{~A}$, more often have irregular endometrial-myometrial junction, non-uniform echogenicity and heterogeneous endometrium without cysts, color score 4, and multiple vessels with multifocal origin but less often have color score 1, and multiple vessels with focal origin.

Table 3 shows the sonographic features of low-risk and high-risk cancer (divided into three categories). With higher stage and grade tumors became bigger (volume and endometrial thickness), the endometrial myometrial junction was less often regular, endometrial echogenicity less often uniform, color score increased, and the multiple, multifocal vessel pattern was more prevalent. The strongest discriminators between low and high-risk cancer were tumor size (endometrial thickness and volume), color score, vessel-pattern, and endometrial/myometrial junction. Figure 2 shows ultrasound images of endometrioid tumors of different stage and grade. 
Endometrial grayscale and ultrasound morphology and vascularization on color Doppler differed between women with endometrial thickness $<15 \mathrm{~mm}$ and $\geq 15 \mathrm{~mm}$. Women with endometrial thickness $<15 \mathrm{~mm}$ more often had regular endometrial-myometrial junction $(37 \%, 249 / 675$ vs. 14\%, 110/803), uniform endometrial echogenicity (50\%, $340 / 675$ vs. $28 \%, 221 / 803)$, and hyperechogenic endometrium (42\%, 284/675 vs. $18 \%$, 114/803), while color score 3 or 4 (41\%, 275/675 vs. $79 \%, 633 / 803)$ and multiple vessels with multifocal origin were less prevalent (20\%, 138/675 vs. 55\%, 439/803) as compared to those with an endometrial thickness of $\geq 15 \mathrm{~mm}$.

Table 4 shows the sonographic characteristics of non-endometrioid tumors (clear-cell carcinoma, serous carcinoma, mixed cell carcinoma and carcinosarcoma). Since there were only seven women with undifferentiated tumors, we decided to exclude them from the table. Although low numbers for non-endometroid tumors were found, carcinosarcomas and clear-cell carcinomas appeared larger than other nonendometrioid tumors. Uniform echogenicity was more prevalent in serous carcinomas but less often seen in mixed cell carcinomas than in other types of non-endometrioid tumors. Figure 3 shows ultrasound images of endometrial cancer of non-endometrioid type. 


\section{Discussion}

The aim of this large prospective multicenter-study was to describe the sonographic features of endometrial cancer in relation to tumor stage and grade using the IETA consensus nomenclature. ${ }^{9}$ In endometrioid tumors a clear difference was found in morphological features between well, moderately and poorly differentiated tumors. With increasing grade and stage, tumors were larger, endometrial/myometrial junction less frequently regular, echogenicity less frequently uniform, and color score higher (Table 2 and 3, and supplementary Table 2). Non-endometrioid tumors were in general larger than endometrioid tumors, the vascularity was similar to grade 3 endometrioid tumors, but grayscale morphology was similar to a grade 1-2 endometrioid tumors (Table 2 and 4).

The strength of this study is the large study population, the prospective design, all examiners being experienced, the use of a standardized ultrasound examination protocol, and an internet based research protocol, into which cases could not be included unless all data were complete, the latter improving the quality of data. The large sample size and the multicenter design increase the likelihood that our results are generalizable. Moreover, to the best of our knowledge, this is the first detailed description of the sonographic features of non-endometrioid endometrial cancers using a standardized ultrasound terminology.

Our results with regard to absolute tumor size and volume must be interpreted with caution, because most women had undergone various biopsy procedures, before the ultrasound examination. Some might argue that it is a limitation that all examinations were done by ultrasound experts impeding the generalizability of the results. However according to the ESGO/ESMO/ ESTRO consensus statement assessment of extension of 
endometrial malignancies and identification of high risk cases should be performed by ultrasound experts, ${ }^{5}$ considering they assess tumor extension more accurately and reproducibly than gynecologists not specialized in ultrasound imaging. ${ }^{14}$

It is important to emphasize that this is a purely descriptive study on endometrial ultrasound morphology and vascularization and not a study on discriminative performance of different ultrasound variables. No single sonographic parameter had more than a moderate ability to predict high risk disease, and thus cannot on its own be used for discriminative purposes. This does not exclude that some sonographic parameters could be of value in a multivariable analysis, or to improve diagnostic confidence when subjectively assessing deep myometrial invasion and cervical stromal invasion. As part of the IETA4 collaboration we attempt to construct risk prediction models for lymph node metastases and high-risk disease, but this is outside the scope of this paper.

In agreement with our results a smaller series $(n=144)$ previously demonstrated that grayscale and vascular morphological characteristics of endometrial cancer were related to tumor stage, grade, and size, advanced tumors more often manifesting a mixed or hypoechogenic echogenicity, high color score and multiple vessels of multifocal origin. ${ }^{15}$

We found that tumor size appeared to be the single strongest ultrasound predictor of high risk disease. Other studies have also found that tumor size according to the hysterectomy specimen ${ }^{16}$ or MRI ${ }^{17}$, correlates to lymph node metastases, ${ }^{16,17}$ and disease free survival in women with endometrial cancer. ${ }^{16}$

In our study, we found that tumors $<15 \mathrm{~mm}$ had a regular endometrial-myometrial junction in $37 \%$ of cases and a hyperechoic endometrial echogenicity in $42 \%$. These are 
also typical features of endometrial hyperplasia. ${ }^{18}$ This is in line with a previous study showing that it was difficult to differentiate between benign and malignant endometrium in women with postmenopausal bleeding if the endometrium measured $<15 \mathrm{~mm} .{ }^{19}$ Even though an irregular endometrial-myometrial junction is a feature of endometrial carcinoma ${ }^{15,19-23}$, we found it to be regular in $32 \%(299 / 911)$ of stage $1 \mathrm{~A}$ cancers, which is in agreement with the $27-30 \%$ found in previous publications. ${ }^{15,23}$ Future IETA studies could investigate if typical ultrasound features of premalignant endometrial lesions exist.

We found that the color score increased with increasing grade and stage. Others too have reported that a high color density ${ }^{24}$ or color score ${ }^{15,25}$ is associated with higher endometrial cancer stage ${ }^{15,24}$ and presence of nodal metastasis, ${ }^{25}$ and that multiple vessels with multifocal origin are associated with higher tumor stage, higher grade, nonendometrioid tumors, larger tumor size, and to an infiltrative tumor growth pattern. ${ }^{15}$ The higher prevalence of a multiple vessel pattern in high-risk tumors is interesting. Angiogenesis, as measured by micro-vessel density, has been demonstrated to play a role in endometrial cancer prognosis. ${ }^{26}$ Vascular proliferation seems to be related to aggressive tumors and decreased survival. ${ }^{27}$ It would be interesting to investigate in future studies if endometrial tumors richly vascularized with the multiple, multifocal vessel pattern on ultrasound have an increased expression of angiogenic markers and/or are associated with lymphovascular space invasion.

Some 30 years ago Bokhman and colleagues hypothesized that there are two pathogenic types of endometrial cancer: type I and type II. ${ }^{28}$ Today we know that the situation is more complex and that histopathological assessment of endometrial tumors is only 
moderately reproducible within and between pathologists, indicating a need for more specific and accurate techniques to classify endometrial cancers. ${ }^{29}$ Based on The Cancer Genome Atlas (TCGA), research teams have developed molecular classifiers to identify four prognostically distinct molecular subgroups of endometrial cancer (Polymerase- $\varepsilon$ 'POLE' ultramutated, microsatellite instability hypermutated, copy number low, and copy number high). ${ }^{30-32}$ It remains to be shown if sonographic morphology correlates to the genome based classification, and if the combination of ultrasound and molecular information can be used to optimize and personalize the management of women with endometrial cancer.

In conclusion, this study shows that sonomorphological features described using IETAterminology ${ }^{9}$ are associated with grade and stage and differ between high and low risk cancer. It remains to be shown if adding assessment of endometrial gray scale ultrasound morphology and vascularization on color Doppler to assessment of myometrial and cervical stroma invasion improves identification of high risk disease. 


\section{Acknowledgements:}

We thank Dr Rossi, Department of Obstetrics and Gynecology, Udine, Italy, Dr Erdodi and Dr Jakab, University of Debrcen, Faculty of Medicine, Department of Obstetrics and Gynecology, Debrecen, Hungary for contributing with cases to this study. The study was supported by: Swedish governmental grants; Avtal om Läkarutbildning och Forskning (ALF), ALF-Region Skåne, ALF-Stockholm County (grant no 550411), Cancer research funding from 'Radiumhemmet' Stockholm Sweden (grant no 154112), Flemish Governmental grant: IWT: TBM IETA (grant no 130256), and KU Leuven Internal Funds (grant no C16/15/059). 
Legends:

Supplementary Figure 1: IETA definitions and terminology using unenhanced sonography and sonohysterography.

Figure 1. Endometrial tumor measurements; a/distance from outer cervical os to lower margin of the tumor in the sagital plane, $b$ / anteroposterior diameter of the uterus, antero-posterior (tumor thickness) and cranio-caudal (tumor length) tumor diameters in the sagittal plane, c/ latero-lateral diameter of the uterus (uterine width) and laterolateral tumor diameter (tumor width) in the transverse plane, $d$ / minimal tumor-free margin measured in any plane where the distance from the tumor to the serosa appears to be at its the smallest.

Figure 2. Ultrasound images of endometrioid tumors of different stage and grade; a/ stage IA, grade $1, \mathrm{~b} /$ stage IA, grade $2, \mathrm{c} /$ stage $1 \mathrm{~A}$, grade $3, \mathrm{~d} /$ stage IB, grade 1 , e/ stage II, grade 3 .

Figure 3. Ultrasound images of endometrial cancer of non-endometrioid histological type; a/ carcinosarcoma, stage IA, b/ carcinosarcoma, stage IB, c/ carcinosarcoma, stage II, d/ clear cell carcinoma, stage IA, e/ clear cell carcinoma, stage IIIA, f/ serous carcinoma, stage IA, g/ serous carcinoma, stage IV, h/ mixed cell carcinoma, stage IIIC. 


\section{References}

1. Ferlay J, Soerjomataram I, Dikshit R, Eser S, Mathers C, Rebelo M, Parkin DM, Forman D and Bray F. Cancer incidence and mortality worldwide: sources, methods and major patterns in GLOBOCAN 2012. Int J Cancer; 136: E359-386.

$2 . \quad$ Benedetti Panici P, Basile S, Maneschi F, Alberto Lissoni A, Signorelli M, Scambia G, Angioli R, Tateo S, Mangili G, Katsaros D, Garozzo G, Campagnutta E, Donadello N, Greggi S, Melpignano M, Raspagliesi F, Ragni N, Cormio G, Grassi R, Franchi M, Giannarelli D, Fossati R, Torri V, Amoroso M, Croce C and Mangioni C. Systematic pelvic lymphadenectomy vs. no lymphadenectomy in early-stage endometrial carcinoma: randomized clinical trial. J Natl Cancer Inst 2008; 100: 1707-1716.

3. Doll KM, Tseng J, Denslow SA, Fader AN and Gehrig PA. High-grade endometrial cancer: revisiting the impact of tumor size and location on outcomes. Gynecol Oncol 2014; 132: 44-49.

4. Pecorelli S. Revised FIGO staging for carcinoma of the vulva, cervix, and endometrium. Int J Gynaecol Obstet 2009; 105: 103-104.

$5 . \quad$ Colombo N, Creutzberg C, Amant F, Bosse T, Gonzalez-Martin A, Ledermann J, Marth C, Nout R, Querleu D, Mirza MR and Sessa C. ESMO-ESGO-ESTRO Consensus Conference on Endometrial Cancer: diagnosis, treatment and follow-up. Ann Oncol 2016; 27: 16-41.

6. Epstein E and Blomqvist L. Imaging in endometrial cancer. Best Pract Res Clin Obstet Gynaecol 2014; 28: 721-739.

7. Fischerova D and Cibula D. Ultrasound in gynecological cancer: is it time for re-evaluation of its uses? Curr Oncol Rep 2015; 17: 28. DOI 10.1007/s11912-015-0449-x. 8. Haldorsen IS and Salvesen HB. What Is the Best Preoperative Imaging for Endometrial Cancer? Curr Oncol Rep 2016; 18: 25. DOI 10.1007/s11912-016-0506-0 10.1007/s11912-016-0506-0 [pii].

9. Leone FP, Timmerman D, Bourne T, Valentin L, Epstein E, Goldstein SR, Marret H, Parsons AK, Gull B, Istre O, Sepulveda W, Ferrazzi E and Van den Bosch T. Terms, definitions and measurements to describe the sonographic features of the endometrium and intrauterine lesions: a consensus opinion from the International Endometrial Tumor Analysis (IETA) group. Ultrasound Obstet Gynecol 2010; 35: 103-112.

10. Installe AJ, Van den Bosch T, De Moor B and Timmerman D. Clinical data miner: an electronic case report form system with integrated data preprocessing and machinelearning libraries supporting clinical diagnostic model research. JMIR Med Inform 2014; 2: e28.

11. C. M. Kurman RJ, Herrington CS, Young RH. WHO Classification of Tumours of Female Reproductive Organs, C. M. Kurman RJ, Herrington CS, Young RH (eds). WHO IARC, WHO Press, Geneva, 2014.

12. Van Calster B, Van Belle V, Vergouwe Y and Steyerberg EW. Discrimination ability of prediction models for ordinal outcomes: relationships between existing measures and a new measure. Biom J 2012; 54: 674-685.

13. Newcombe RG. Interval estimation for the difference between independent proportions: comparison of eleven methods. Stat Med 1998; 17: 873-890.

14. Eriksson LS, Lindqvist PG, Floter Radestad A, Dueholm M, Fischerova D, Franchi D, Jokubkiene L, Leone FP, Savelli L, Sladkevicius P, Testa AC, Van den Bosch T, Ameye L and Epstein E. Transvaginal ultrasound assessment of myometrial and cervical stromal invasion in women with endometrial cancer: interobserver reproducibility among ultrasound experts and gynecologists. Ultrasound Obstet Gynecol 2015; 45: 476-482. 
15. Epstein E, Van Holsbeke C, Mascilini F, Masback A, Kannisto P, Ameye L, Fischerova D, Zannoni G, Vellone V, Timmerman D and Testa AC. Gray-scale and color Doppler ultrasound characteristics of endometrial cancer in relation to stage, grade and tumor size. Ultrasound Obstet Gynecol 2011; 38: 586-593.

16. Mahdi H, Munkarah AR, Ali-Fehmi R, Woessner J, Shah SN and MoslemiKebria M. Tumor size is an independent predictor of lymph node metastasis and survival in early stage endometrioid endometrial cancer. Arch Gynecol Obstet 2015; 292: 183-190.

17. Bourgioti C, Chatoupis K, Tzavara C, Antoniou A, Rodolakis A and Moulopoulos LA. Predictive ability of maximal tumor diameter on MRI for high-risk endometrial cancer. Abdom Radiol (NY) 2016; 41: 2484-2495.

18. Hulka CA, Hall DA, McCarthy K and Simeone JF. Endometrial polyps, hyperplasia, and carcinoma in postmenopausal women: differentiation with endovaginal sonography. Radiology 1994; 191: 755-758.

19. Epstein E, Skoog L, Isberg PE, De Smet F, De Moor B, Olofsson PA, Gudmundsson S and Valentin L. An algorithm including results of gray-scale and power Doppler ultrasound examination to predict endometrial malignancy in women with postmenopausal bleeding. Ultrasound Obstet Gynecol 2002; 20: 370-376.

20. Epstein E and Valentin L. Gray-scale ultrasound morphology in the presence or absence of intrauterine fluid and vascularity as assessed by color Doppler for discrimination between benign and malignant endometrium in women with postmenopausal bleeding. Ultrasound Obstet Gynecol 2006; 28: 89-95.

21. Opolskiene G, Sladkevicius P and Valentin L. Ultrasound assessment of endometrial morphology and vascularity to predict endometrial malignancy in women with postmenopausal bleeding and sonographic endometrial thickness $>$ or $=4.5 \mathrm{~mm}$. Ultrasound Obstet Gynecol 2007; 30: 332-340..

22. Sheikh M, Sawhney S, Khurana A and Al-Yatama M. Alteration of sonographic texture of the endometrium in post-menopausal bleeding. A guide to further management. Acta Obstet Gynecol Scand 2000; 79: 1006-1010.

23. Fischerova D, Fruhauf F, Zikan M, Pinkavova I, Kocian R, Dundr P, Nemejcova $\mathrm{K}$, Dusek L and Cibula D. Factors affecting sonographic preoperative local staging of endometrial cancer. Ultrasound Obstet Gynecol 2014; 43: 575-585.

24. Sawicki V, Spiewankiewicz B, Stelmachow J and Cendrowski K. Color Doppler assessment of blood flow in endometrial cancer. Eur J Gynaecol Oncol 2005; 26: 279-284.

25. Testa AC, Ciampelli M, Mastromarino C, Lopez R, Zannoni G, Ferrandina G and Scambia G. Intratumoral color Doppler analysis in endometrial carcinoma: is it clinically useful? Gynecol Oncol 2003; 88: 298-303.

26. Salvesen HB, Iversen OE and Akslen LA. Independent prognostic importance of microvessel density in endometrial carcinoma. Br J Cancer 1998; 77: 1140-1144.

27. Stefansson IM, Salvesen HB and Akslen LA. Vascular proliferation is important for clinical progress of endometrial cancer. Cancer Res 2006; 66: 3303-3309.

28. Bokhman JV. Two pathogenetic types of endometrial carcinoma. Gynecol Oncol 1983; 15: 10-17.

29. Gilks CB, Oliva E and Soslow RA. Poor interobserver reproducibility in the diagnosis of high-grade endometrial carcinoma. Am J Surg Pathol 2013; 37: 874-881.

30. Kandoth C, Schultz N, Cherniack AD, Akbani R, Liu Y, Shen H, Robertson

AG, Pashtan I, Shen R, Benz CC, Yau C, Laird PW, Ding L, Zhang W, Mills GB,

Kucherlapati R, Mardis ER and Levine DA. Integrated genomic characterization of endometrial carcinoma. Nature 2013; 497: 67-73.

31. Stelloo E, Bosse T, Nout RA, MacKay HJ, Church DN, Nijman HW, Leary A, Edmondson RJ, Powell ME, Crosbie EJ, Kitchener HC, Mileshkin L, Pollock PM, Smit VT 
and Creutzberg CL. Refining prognosis and identifying targetable pathways for high-risk endometrial cancer; a TransPORTEC initiative. Mod Pathol 2015; 28: 836-844.

32. Talhouk A and McAlpine JN. New classification of endometrial cancers: the development and potential applications of genomic-based classification in research and clinical care. Gynecol Oncol Res Pract 2016; 3: 14.

Table 1 Demographic background data and histological outcome at hysterectomy* $(n=1538)$

\begin{tabular}{|c|c|}
\hline Age & $65(27-98)$ \\
\hline Age at menopause ${ }^{\dagger}$ & $51(28-65)$ \\
\hline Body Mass Index & $28.4(16-67)$ \\
\hline Parity & $2(0-10)$ \\
\hline 0 & $284(18.5 \%)$ \\
\hline 1 & $315(20.5 \%)$ \\
\hline$\geq 2$ & $939(61.1 \%)$ \\
\hline Use of any hormone replacement therapy or local estrogens & $178(11.6 \%)$ \\
\hline Postmenopausal & $1377(89.5 \%)$ \\
\hline with abnormal bleeding & $1168(84.8 \%)$ \\
\hline Premenopausal & $161(10.5 \%)$ \\
\hline with abnormal bleeding & $128(79.5 \%)$ \\
\hline \multicolumn{2}{|l|}{ Stage } \\
\hline IA & $936(60.9 \%)$ \\
\hline IB & $324(21.1 \%)$ \\
\hline II & $86(5.6 \%)$ \\
\hline IIIA & $32(2.1 \%)$ \\
\hline IIIB & $18(1.2 \%)$ \\
\hline IIIC1 & $73(4.7 \%)$ \\
\hline IIIC2 & $46(3.0 \%)$ \\
\hline IV & $23(1.5 \%)$ \\
\hline \multicolumn{2}{|l|}{ Histological type, grade } \\
\hline Endometrioid $\ddagger$ & $1330(86.5 \%)$ \\
\hline Grade 1 & $603(45.3 \%)$ \\
\hline Grade 2 & $512(38.5 \%)$ \\
\hline Grade 3 & $215(16.2 \%)$ \\
\hline Non-endometrioid & $208(13.5 \%)$ \\
\hline Serous & $91(43.8 \%)$ \\
\hline Carcinosarcoma & $41(19.7 \%)$ \\
\hline Clear cell carcinoma & $33(15.9 \%)$ \\
\hline Mixed cell carcinoma & $36(17.3 \%)$ \\
\hline Undifferentiated & $7(3.4 \%)$ \\
\hline
\end{tabular}


Results are presented as median (range) or $\mathrm{n}(\%)$

* In 30 cases outcome was based on: biopsy $(n=4), D \& C(n=9)$ or hysteroscopic resection $(n=17)$, as hysterectomy showed no remaining cancer: normal findings $(n=17)$,

atypical hyperplasia $(n=12)$ or simple hyperplasia $(n=1)$.

${ }^{\dagger}$ In postmenopausal women. ¥Including 45 endometrioid tumors with squamous differentiation and 2 mucinous carcinomas. 


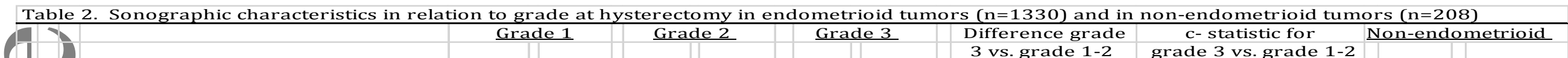

All women ( $n=1538)$

Endometrium

Deasurable

not visible

Tumor

defined

Myometrium
Fibroid present

Adenomyosis yes or uncertain

Cases with visible endometrium ( $n=14$

Endometrial-myometrial junction

regular

ihterrupted

undefined

Endometrial morphology

Uniform

Non-uniform

hyperechorm

hyperechogenic

hypoechogen

three-layer pattern

Within non-uniform

homogeneous, regular cystic areas

homogeneous, irregular cystic areas

heterogeneous no cystic areas

heterogeneous with regular cysts

heterogeneous with irregular cysts

Bright edge present

Endometrial mid line

linear

non linear

irregular

Golor score

color score 1

color score 2

color score 4

Vascular pattern

no flow

single vessel without branching

ingle vessel with branching

multiple vessels, focal

multiple vessels, multifocal

scattered vessels

Endometrial thickness, $\mathrm{mm}(\mathrm{n}=1429)$

Endometrial thickness, $\mathrm{mm}(\mathrm{n}$

Grade 2 grade 3 vs. grade (95\% CI)

\begin{tabular}{c|ccc}
$(n=603)$ & $n$ & $n$ & $\%$ \\
\hline & $(n=512)$ & $(n=215)$
\end{tabular}

\begin{tabular}{|c|c|c|c|c|c|}
\hline 572 & $94.9 \%$ & 473 & $92.4 \%$ & 193 & $89.8 \%$ \\
\hline 19 & $3.2 \%$ & 17 & $3.3 \%$ & 11 & $5.1 \%$ \\
\hline 12 & $2.0 \%$ & 22 & $4.3 \%$ & 11 & $5.1 \%$ \\
\hline 481 & $79.8 \%$ & 429 & $83.8 \%$ & 186 & $86.5 \%$ \\
\hline 229 & $38.0 \%$ & 183 & $35.7 \%$ & 69 & $32.1 \%$ \\
\hline 70 & $11.6 \%$ & 35 & $6.8 \%$ & 9 & $4.2 \%$ \\
\hline$a=591)$ & & $(n=490$ & & $(n=204$ & \\
\hline
\end{tabular}

214

\begin{tabular}{l|l|l|l|}
214 & $36.2 \%$ & 94 & $19.2 \%$
\end{tabular}

\begin{tabular}{l|l|l|l|}
188 & $31.8 \%$ & 181 & $36.9 \%$ \\
\hline
\end{tabular}

\begin{tabular}{|c|c|c|c|}
161 & $27.2 \%$ & 187 & $38.2 \%$ \\
\hline 28 & $4.7 \%$ & 28 & $5.7 \%$
\end{tabular}

\begin{tabular}{|l|l|l|}
\hline 270 & $45.7 \%$ & 490 \\
\hline 321 & $54.3 \%$ & 329 \\
\hline
\end{tabular}

321

219

41

15

21

15

18

81

28
8
27

\begin{tabular}{|c|c|c|c|c|}
\hline 8 & 15 & $3.1 \%$ & 4 & $2.0 \%$ \\
\hline
\end{tabular}

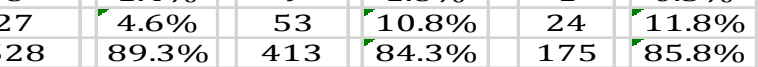

\begin{tabular}{|l|l|l|}
\hline & 413 & $-84.3 \%$
\end{tabular}

\begin{tabular}{l|l|l|l|}
157 & $26.6 \%$ & 87 & $17.8 \%$
\end{tabular}

\begin{tabular}{l|l|l|l|}
140 & $23.7 \%$ & 76 & $15.5 \%$ \\
\hline
\end{tabular}

\begin{tabular}{ll|l|}
$29.9 \%$ & 192 & $-39.2 \%$ \\
\hline
\end{tabular}

\begin{tabular}{ll|l|l|}
\hline $19.8 \%$ & 135 & $27.6 \%$
\end{tabular}

\begin{tabular}{l|l|l|l|}
157 & $26.6 \%$ & 87 & $17.8 \%$
\end{tabular}

$\begin{array}{lll}4.9 \% & 26 & 5.3 \% \\ 7.1 \% & 37 & 7.6 \%\end{array}$

\begin{tabular}{|c|c|c|}
\hline $7.1 \%$ & 37 & $7.6 \%$ \\
\hline $12.7 \%$ & 73 & $14.9 \%$ \\
\hline $33.2 \%$ & 202 & $41.2 \%$
\end{tabular}

\begin{tabular}{|c|c|c|}
\hline $33.2 \%$ & 202 & $-41.2 \%$ \\
\hline
\end{tabular}

$\begin{array}{lll}15.6 \% & 63 & -12.9 \%\end{array}$

$\begin{array}{lll}0.0 \% & 2 & 0.4 \%\end{array}$

$-1-66-17.0-1-89$

\begin{tabular}{cc|c|c|}
$1-89$ & 23.5 & $1-68$ \\
$<1-318$ & 14.9 & $<1-222$ \\
\hline
\end{tabular} $+2 \%(-1$ to +6$)$ $+2 \%(0$ to +6$)$

$+5 \%(-1$ to +10$)$

$-5 \%(-12$ to +2$)$

$-5 \%(-8$ to -1$)$

$23 \quad 11.3 \%$

$\begin{aligned} & 68 \\ & 96\end{aligned}-33.3 \%$

$17 \quad 8.3 \%$

$17 \%(-22$ to -12$)$

$0 \%(-7$ to +7$)$

$+15 \%(+7$ to +22$)$

$+3 \%(0$ to +8$)$

$-12 \%(-18$ to -5$)$

$+10 \%(-7$ to +27$)$

$-16 \%(-21$ to -9$)$

$+2 \%(+1$ to +5$)$

$2 \%(-2$ to +7$)$

$-1 \%(-2$ to +1$)$

$-1 \%(-2$ to +2$)$

$0 \%(-2$ to +3$)$

$+11 \%(+4$ to +18$)$

$+1 \%(-1$ to +4$)$

$+1 \%(-2$ to +5$)$

$-2 \%(-6$ to +3$)$

$-2 \%(-4$ to +1$)$

$-1 \%(-2$ to +1$)$

$+5 \%(-1$ to +10$)$

$-2 \%(-7$ to +3$)$

$22 \quad-10.8 \%$

$37-18.1 \%$

$65 \quad 31.9 \%$

$-12 \%(-16$ to -6$)$

$-2 \%(-7$ to +4$)$

$+16 \%(+9$ to +23$)$

$22-10.8 \%$

$6 \quad 2.9 \%$

$14 \div 6.9 \%$

$94-46.1 \%$

$5 \quad 12.3 \%$

$12.3 \%$

$<1-286-7.7$

$23.5<1-68$
$4.9<1-222$

$-12 \%(-16$ to -6$)$

$-2 \%(-4$ to -1$)$

$-1 \%(-4$ to +4$)$

$+10 \%(+2$ to +17$)$

$-2 \%(-7$ to +3$)$

$0 \%(-1$ to +2$)$

$+9(+7$ to +12$)$

$+9(+5$ to +14$)$

$0.66(0.62-0.70)$

$0.61(0.57-0.65)$

$0.51(0.49-0.53)$

$0.52(0.49-0.55)$

$0.60(0.56-0.63)$

$0.54(0.51-0.58)$

moderate vascularity - color score 3 , abundant vascularity - color score 4

This article is protected by copyright. All rights reserved.

\begin{tabular}{|c|c|}
\hline \multicolumn{2}{|c|}{$(n=208)$} \\
\hline 190 & $91.3 \%$ \\
\hline 2 & $1.0 \%$ \\
\hline 16 & $7.7 \%$ \\
\hline 179 & $86.1 \%$ \\
\hline 70 & $33.7 \%$ \\
\hline 7 & $3.4 \%$ \\
\hline$(n=192$ & \\
\hline 28 & $14.6 \%$ \\
\hline 72 & $37.5 \%$ \\
\hline 80 & $41.7 \%$ \\
\hline 12 & $6.3 \%$ \\
\hline 74 & $38.5 \%$ \\
\hline 118 & $61.5 \%$ \\
\hline 51 & $26.6 \%$ \\
\hline 5 & $2.6 \%$ \\
\hline 17 & $8.9 \%$ \\
\hline 1 & $0.5 \%$ \\
\hline 4 & $2.1 \%$ \\
\hline 11 & $5.7 \%$ \\
\hline 82 & $42.7 \%$ \\
\hline 4 & $2.1 \%$ \\
\hline 17 & $8.9 \%$ \\
\hline 29 & $15.1 \%$ \\
\hline 5 & $2.6 \%$ \\
\hline o & $0.0 \%$ \\
\hline 10 & $5.2 \%$ \\
\hline 177 & $92.2 \%$ \\
\hline 26 & $=13.5 \%$ \\
\hline 25 & $13.0 \%$ \\
\hline 67 & $34.9 \%$ \\
\hline 74 & $38.5 \%$ \\
\hline 26 & $13.5 \%$ \\
\hline 6 & $3.1 \%$ \\
\hline 11 & $5.7 \%$ \\
\hline 49 & $25.5 \%$ \\
\hline 84 & $43.8 \%$ \\
\hline 16 & $8.3 \%$ \\
\hline $\mathbf{O}$ & $0.0 \%$ \\
\hline 21.0 & $2-96$ \\
\hline 14.8 & $<1-381$ \\
\hline
\end{tabular}

14.8


Table 3. Sonographic characteristics in women with low risk $(n=762)$ and high risk $(n=776)$ cancer

\begin{tabular}{|c|c|c|c|c|c|c|c|c|c|c|c|}
\hline & & \multicolumn{2}{|c|}{ Low risk Cancer } & \multicolumn{5}{|c|}{ High-risk cancer } & & \multirow{2}{*}{ Difference: High } & \multirow[b]{2}{*}{ c- statistic for } \\
\hline & & \multicolumn{2}{|c|}{ Stage $1 \mathrm{~A}$} & \multicolumn{2}{|c|}{ Stage 1A, Grade 3} & \multicolumn{4}{|c|}{ Stage $\geq 1 \mathrm{~B} \quad$ Stage $\geq 1 \mathrm{~B}$, Grade 3} & & \\
\hline & & \multicolumn{2}{|c|}{ Grade 1-2 } & \multicolumn{2}{|c|}{ non-endometroid } & \multicolumn{2}{|c|}{ Grade 1-2 } & \multicolumn{2}{|c|}{ non-endometroid } & vs. Low-Risk & High vs. Low-Risk \\
\hline & & $\mathrm{n}$ & $\%$ & $\mathrm{n}$ & $\%$ & $\mathrm{n}$ & $\%$ & $\mathrm{n}$ & $\%$ & $(95 \% \mathrm{CI})$ & $(95 \% \mathrm{CI})$ \\
\hline \multicolumn{2}{|r|}{ All cases $(n=1539)$} & \multicolumn{2}{|c|}{$(n=762)$} & \multicolumn{2}{|c|}{$(n=174)$} & $(n=$ & 353) & $(n=$ & 249) & & \\
\hline & Endometrium & & & & & & & & & & \\
\hline & measurable & 733 & $96.2 \%$ & 156 & $89.7 \%$ & 312 & $88.4 \%$ & 227 & $91.2 \%$ & $-7 \%(-9$ to -4$)$ & $0.53(0.52-0.55)$ \\
\hline & not measurable & 15 & $2.0 \%$ & 7 & $4.0 \%$ & 21 & $5.9 \%$ & 6 & $2.4 \%$ & $+2 \%(+1$ to +4$)$ & \\
\hline & not visible & 14 & $1.8 \%$ & 11 & $6.3 \%$ & 20 & $5.7 \%$ & 16 & $6.4 \%$ & $+4 \%(+2$ to +6$)$ & \\
\hline & Tumor & & & & & & & & & & \\
\hline & defined & 598 & $78.5 \%$ & 141 & $81.0 \%$ & 312 & $88.4 \%$ & 224 & $90.0 \%$ & $+9 \%(+5$ to +13$)$ & $0.54(0.52-0.56)$ \\
\hline & Myometrium & & & & & & & & & & \\
\hline & Fibroid present & 298 & $39.1 \%$ & 61 & $35.1 \%$ & 114 & $32.3 \%$ & 78 & $31.3 \%$ & $-7 \%(-11$ to -2$)$ & $0.53(0.51-0.56)$ \\
\hline & Adenomyosis yes or uncertain & 73 & $9.6 \%$ & 6 & $3.4 \%$ & 32 & $9.1 \%$ & 10 & $4.0 \%$ & $-3 \%(-6$ to -1$)$ & $0.51(0.50-0.52)$ \\
\hline & ases with visible endometrium ( $\mathrm{n}=1477$ ) & & 748) & $(\mathrm{n}=$ & 163) & $(n=3$ & 333) & & 233) & & \\
\hline & Endometrial-myometrial junction & & & & & & & & & & \\
\hline & regular & 265 & $35.4 \%$ & 34 & $20.9 \%$ & 43 & $12.9 \%$ & 17 & $7.3 \%$ & $-23 \%(-27$ to -18$)$ & $0.61(0.59-0.64)$ \\
\hline & irregular & 237 & $31.7 \%$ & 56 & $34.4 \%$ & 132 & $39.6 \%$ & 84 & $36.1 \%$ & $+6 \%(+1$ to +11$)$ & \\
\hline & interrupted & 225 & $30.1 \%$ & 69 & $42.3 \%$ & 123 & $36.9 \%$ & 107 & $45.9 \%$ & $+11 \%(+6$ to +16$)$ & \\
\hline & undefined & 21 & $2.8 \%$ & 4 & $2.5 \%$ & 35 & $10.5 \%$ & 25 & $10.7 \%$ & $+6 \%(+4$ to +8$)$ & \\
\hline & Endometrial morphology & & & & & & & & & & \\
\hline & uniform & 321 & $42.9 \%$ & 63 & $38.7 \%$ & 109 & $32.7 \%$ & 68 & $29.2 \%$ & $-10 \%(-15$ to -5$)$ & $0.55(0.53-0.58)$ \\
\hline & non-uniform & 427 & $57.1 \%$ & 100 & $61.4 \%$ & 224 & $67.3 \%$ & 165 & $70.8 \%$ & $+7(+1$ to +13$)$ & \\
\hline & within uniform & & & & & & & & & & $0.61(0.57-0.64)$ \\
\hline & hyperechogenic & 267 & $35.7 \%$ & 43 & $26.4 \%$ & 75 & $22.5 \%$ & 41 & $17.6 \%$ & $-14 \%(-18$ to -9$)$ & \\
\hline & hypoechogenic & 2 & $0.3 \%$ & 4 & $2.5 \%$ & 0 & $0.0 \%$ & 6 & $2.6 \%$ & $+1 \%(0$ to +2$)$ & \\
\hline & isoechogenic & 43 & $5.7 \%$ & 15 & $9.2 \%$ & 34 & $10.2 \%$ & 21 & $9.0 \%$ & $+4 \%(+1$ to +7$)$ & \\
\hline & three-layer pattern & 9 & $1.2 \%$ & 1 & $0.6 \%$ & 0 & $0.0 \%$ & 0 & $0.0 \%$ & $-1 \%(-2$ to 0$)$ & \\
\hline & within non-unifrom & & & & & & & & & & $0.55(0.53-0.57)$ \\
\hline & homogeneous, regular cystic areas & 20 & $2.7 \%$ & 5 & $3.1 \%$ & 1 & $0.3 \%$ & 2 & $0.9 \%$ & $-2 \%(-3$ to 0$)$ & \\
\hline & homogeneous, irregular cystic areas & 30 & $4.0 \%$ & 8 & $4.9 \%$ & 5 & $1.5 \%$ & 8 & $3.4 \%$ & $-1 \%(-3$ to +1$)$ & \\
\hline & heterogeneous no cystic areas & 337 & $45.1 \%$ & 78 & $47.9 \%$ & 195 & $58.6 \%$ & 128 & $54.9 \%$ & $+10 \%(+5$ to +15$)$ & \\
\hline & heterogeneous with regular cysts & 16 & $2.1 \%$ & 4 & $2.5 \%$ & 4 & $1.2 \%$ & 5 & $2.1 \%$ & $0 \%(-2$ to +1$)$ & \\
\hline & heterogeneous with irregular cysts & 24 & $3.2 \%$ & 5 & $3.1 \%$ & 19 & $5.7 \%$ & 22 & $9.4 \%$ & $+3 \%(+1$ to +5$)$ & \\
\hline & Bright edge present & 101 & $13.5 \%$ & 27 & $16.6 \%$ & 48 & $14.4 \%$ & 26 & $11.2 \%$ & $0 \%(-3$ to +4$)$ & $0.50(0.48-0.52)$ \\
\hline & Endometrial mid line & & & & & & & & & & $0.51(0.49-0.53)$ \\
\hline & linear & 36 & $4.8 \%$ & 6 & $3.7 \%$ & 7 & $2.1 \%$ & 3 & $1.3 \%$ & $-3 \%(-5$ to 0$)$ & \\
\hline & non linear & 13 & $1.7 \%$ & 1 & $0.6 \%$ & 4 & $1.2 \%$ & 0 & $0.0 \%$ & $-1 \%(-2$ to 0$)$ & \\
\hline & irregular & 54 & $7.2 \%$ & 14 & $8.6 \%$ & 26 & $7.8 \%$ & 20 & $8.6 \%$ & $-1 \%(-2$ to +4$)$ & \\
\hline & undefined /not seen & 645 & $86.2 \%$ & 142 & $87.1 \%$ & 296 & $88.9 \%$ & 210 & $90.1 \%$ & $+3 \%(-1$ to +6$)$ & \\
\hline & Color score & & & & & & & & & & $0.66(0.63-0.68)$ \\
\hline & color score 1 & 203 & $27.1 \%$ & 34 & $20.9 \%$ & 41 & $12.3 \%$ & 14 & $6.0 \%$ & $-15 \%(-19$ to -11$)$ & \\
\hline & color score 2 & 170 & $22.7 \%$ & 35 & $21.5 \%$ & 46 & $13.8 \%$ & 27 & $11.6 \%$ & $-8 \%(-12$ to -4$)$ & \\
\hline & color score 3 & 252 & $33.7 \%$ & 52 & $31.9 \%$ & 117 & $35.1 \%$ & 80 & $34.3 \%$ & $0 \%(-4$ to +5$)$ & \\
\hline & color score 4 & 123 & $16.4 \%$ & 42 & $25.8 \%$ & 129 & $38.7 \%$ & 112 & $48.1 \%$ & $+22 \%(+18$ to +27$)$ & \\
\hline & Vascular pattern & & & & & & & & & & \\
\hline & no flow & 203 & $27.1 \%$ & 34 & $20.9 \%$ & 41 & $12.3 \%$ & 14 & $6.0 \%$ & $-15 \%(-19$ to -11$)$ & $0.64(0.62-0.67)$ \\
\hline & single vessel without branching & 46 & $6.1 \%$ & 9 & $5.5 \%$ & 9 & $2.7 \%$ & 3 & $1.3 \%$ & $-3 \%(-5$ to -1$)$ & \\
\hline & single vessel with branching & 63 & $8.4 \%$ & 13 & $8.0 \%$ & 16 & $4.8 \%$ & 12 & $5.2 \%$ & $-3 \%(-5$ to 0$)$ & \\
\hline & multiple vessels, focal & 111 & $14.8 \%$ & 47 & $28.8 \%$ & 37 & $11.1 \%$ & 45 & $19.3 \%$ & $+3 \%(-1$ to +7$)$ & \\
\hline & multiple vessels, multifocal & 215 & $28.7 \%$ & 40 & $24.5 \%$ & 183 & $55.0 \%$ & 138 & $59.2 \%$ & $+21 \%(+16$ to +26$)$ & \\
\hline & scattered vessels & 109 & $14.6 \%$ & 20 & $12.3 \%$ & 46 & $13.8 \%$ & 21 & $9.0 \%$ & $-3 \%(-6$ to +1$)$ & \\
\hline & circular vessels & 1 & $0.1 \%$ & 0 & $0.0 \%$ & 1 & $0.3 \%$ & 0 & $0.0 \%$ & $0 \%(-1$ to +1$)$ & \\
\hline & Endometrial thickness, $\mathrm{mm}(\mathrm{n}=1429)$ & 13 & $1-63$ & 15 & $2-96$ & 22 & $2-89$ & 28 & $2-76$ & $+9(+8$ to +11$)$ & $0.72(0.69-0.74)$ \\
\hline & Tumor volume, $\mathrm{ml}(\mathrm{n}=1276)$ & 4.5 & $<1-286$ & 7.3 & $<1-263$ & 12.5 & $<1-317$ & 21 & $<1-381$ & $+10(+8$ to +12$)$ & $0.72(0.70-0.75)$ \\
\hline
\end{tabular}

Number and percentage or median $\mathrm{mm} / \mathrm{ml}$ and range are given.

No vascularity - color score 1 , sparse vascularity - color score 2 , moderate vascularity - color score 3 Abundhis article is protected by copyright. All rights reserved. 
Table 4. Sonographic characteristics of non-endometrioid ( $\mathrm{n}=201^{*}$ ) tumors

\begin{tabular}{|c|c|c|c|c|c|c|c|c|}
\hline & \multicolumn{2}{|c|}{$\begin{array}{l}\text { Clear cell } \\
\text { carcinoma }\end{array}$} & \multicolumn{2}{|c|}{$\begin{array}{l}\text { Carcino } \\
\text { sarcoma }\end{array}$} & \multicolumn{2}{|c|}{$\begin{array}{l}\text { Serous } \\
\text { carcinoma }\end{array}$} & \multicolumn{2}{|c|}{$\begin{array}{l}\text { Mixed cell } \\
\text { carcinoma }\end{array}$} \\
\hline All women $(n=201 *)$ & \multicolumn{2}{|c|}{$(n=33)$} & \multicolumn{2}{|c|}{$(n=41)$} & \multicolumn{2}{|c|}{$(\mathrm{n}=91)$} & \multicolumn{2}{|c|}{$(n=36)$} \\
\hline \multicolumn{9}{|l|}{$\underline{\text { Endometrium }}$} \\
\hline measurable & 30 & $90.9 \%$ & 37 & $90.2 \%$ & 86 & $94.5 \%$ & 31 & $86.1 \%$ \\
\hline not measurable & 0 & $0.0 \%$ & 0 & $0.0 \%$ & 2 & $2.2 \%$ & 0 & $0.0 \%$ \\
\hline not visible & 3 & $9.1 \%$ & 4 & $9.8 \%$ & 3 & $3.3 \%$ & 5 & $13.9 \%$ \\
\hline \multicolumn{9}{|l|}{ Tumor } \\
\hline defined & 25 & $75.8 \%$ & 37 & $90.2 \%$ & 77 & $84.6 \%$ & 34 & $94.4 \%$ \\
\hline not defined & 8 & $24.2 \%$ & 4 & $9.8 \%$ & 14 & $15.4 \%$ & 2 & $5.6 \%$ \\
\hline \multicolumn{9}{|l|}{ Myometrium } \\
\hline Fibroid present & 9 & $27.3 \%$ & 8 & $19.5 \%$ & 39 & $42.9 \%$ & 11 & $30.6 \%$ \\
\hline Adenomyosis yes or uncertain & 0 & $0.0 \%$ & 0 & $0.0 \%$ & 4 & $4.4 \%$ & 3 & $8.3 \%$ \\
\hline Visible endometrium $(\mathrm{n}=186)$ & \multicolumn{2}{|c|}{$(n=30)$} & \multicolumn{2}{|c|}{$(n=37)$} & \multicolumn{2}{|c|}{$(\mathrm{n}=88)$} & \multicolumn{2}{|c|}{$(n=31)$} \\
\hline \multicolumn{9}{|l|}{ Endometrial-myometrial border } \\
\hline regular & 7 & $23.3 \%$ & 5 & $13.5 \%$ & 13 & $14.8 \%$ & 2 & $6.5 \%$ \\
\hline non-regular & 23 & $76.7 \%$ & 32 & $86.5 \%$ & 75 & $85.2 \%$ & 29 & $93.5 \%$ \\
\hline \multicolumn{9}{|l|}{ Endometrial morphology } \\
\hline uniform & 11 & $36.7 \%$ & 12 & $32.4 \%$ & 41 & $46.6 \%$ & 7 & $22.6 \%$ \\
\hline hyperechogenic & 8 & $26.7 \%$ & 7 & $18.9 \%$ & 29 & $33.0 \%$ & 6 & $19.4 \%$ \\
\hline hypo/iso/three layer & 3 & $10.0 \%$ & 5 & $13.5 \%$ & 12 & $13.6 \%$ & 1 & $3.2 \%$ \\
\hline non-uniform & 19 & $63.3 \%$ & 25 & $67.6 \%$ & 47 & $53.4 \%$ & 24 & $77.4 \%$ \\
\hline homogeneous with cysts & 2 & $6.7 \%$ & 4 & $10.8 \%$ & 6 & $6.8 \%$ & 2 & $6.5 \%$ \\
\hline heterogenuous no cysts & 14 & $46.7 \%$ & 12 & $32.4 \%$ & 37 & $42.0 \%$ & 17 & $54.8 \%$ \\
\hline heterogeneous with cysts & 3 & $10.0 \%$ & 9 & $24.3 \%$ & 4 & $4.5 \%$ & 5 & $16.1 \%$ \\
\hline \multicolumn{9}{|l|}{ Bright edge sign } \\
\hline yes & 2 & $6.7 \%$ & 8 & $21.6 \%$ & 12 & $13.6 \%$ & 5 & $16.1 \%$ \\
\hline no & 28 & $93.3 \%$ & 29 & $78.4 \%$ & 76 & $86.4 \%$ & 26 & $83.9 \%$ \\
\hline \multicolumn{9}{|l|}{ Endometrial midline } \\
\hline seen & 5 & $16.7 \%$ & 2 & $5.4 \%$ & 8 & $9.1 \%$ & 2 & $6.5 \%$ \\
\hline undefined /not seen & 25 & $83.3 \%$ & 35 & $94.6 \%$ & 80 & $90.9 \%$ & 29 & $93.5 \%$ \\
\hline \multicolumn{9}{|l|}{ Color score } \\
\hline color score 1 & 3 & $10.0 \%$ & 4 & $10.8 \%$ & 14 & $15.9 \%$ & 4 & $12.9 \%$ \\
\hline color score 2 & 4 & $13.3 \%$ & 3 & $8.1 \%$ & 14 & $15.9 \%$ & 4 & $12.9 \%$ \\
\hline color score 3 & 10 & $33.3 \%$ & 14 & $37.8 \%$ & 31 & $35.2 \%$ & 10 & $32.3 \%$ \\
\hline color score 4 & 13 & $43.3 \%$ & 16 & $43.2 \%$ & 29 & $33.0 \%$ & 13 & $41.9 \%$ \\
\hline \multicolumn{9}{|l|}{ Vascular pattern } \\
\hline no flow & 3 & $10.0 \%$ & 4 & $10.8 \%$ & 14 & $15.9 \%$ & 4 & $12.9 \%$ \\
\hline single + /- branching & 4 & $13.3 \%$ & 2 & $5.4 \%$ & 9 & $10.2 \%$ & 2 & $6.5 \%$ \\
\hline multiple vessels, focal & 11 & $36.7 \%$ & 10 & $27.0 \%$ & 18 & $20.5 \%$ & 7 & $22.6 \%$ \\
\hline multiple vessels, multifocal & 10 & $33.3 \%$ & 20 & $54.1 \%$ & 40 & $45.5 \%$ & 12 & $38.7 \%$ \\
\hline scattered vessels & 2 & $6.7 \%$ & 1 & $2.7 \%$ & 7 & $8.0 \%$ & 6 & $19.4 \%$ \\
\hline Endometrial thickness, $\mathrm{mm}$ & 28.0 & $4-76$ & 39.0 & $7-65$ & 18.0 & $2-71$ & 20.0 & $4-61$ \\
\hline Tumor volume, ml & 16.4 & $<1-341$ & 56.9 & $1-280$ & 8.0 & $<1-202$ & 8.4 & $<1-232$ \\
\hline
\end{tabular}

* Results for undifferentiated tumors ( $\mathrm{n}=7)$ not shown in table. Number and percentage or median $\mathrm{mm} / \mathrm{ml}$ and range are given. No vascularity - color score 1 , sparse vascularity - 
color score 2 , moderate vascularity - color score 3 , abundant vascularity - color score 4

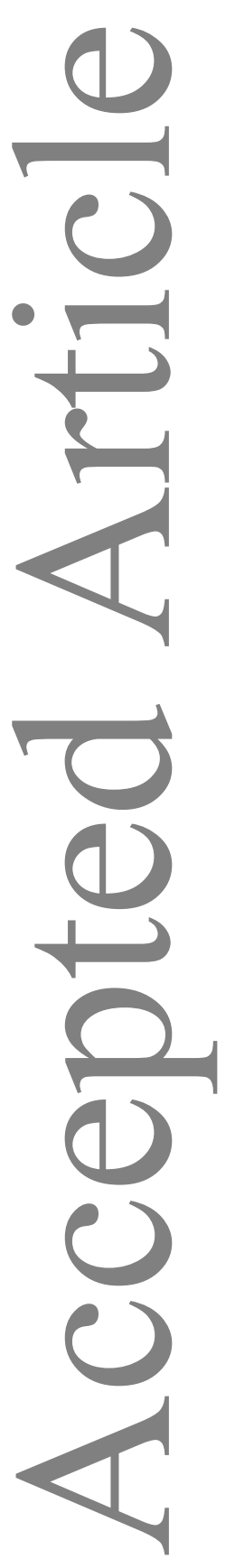

This article is protected by copyright. All rights reserved. 


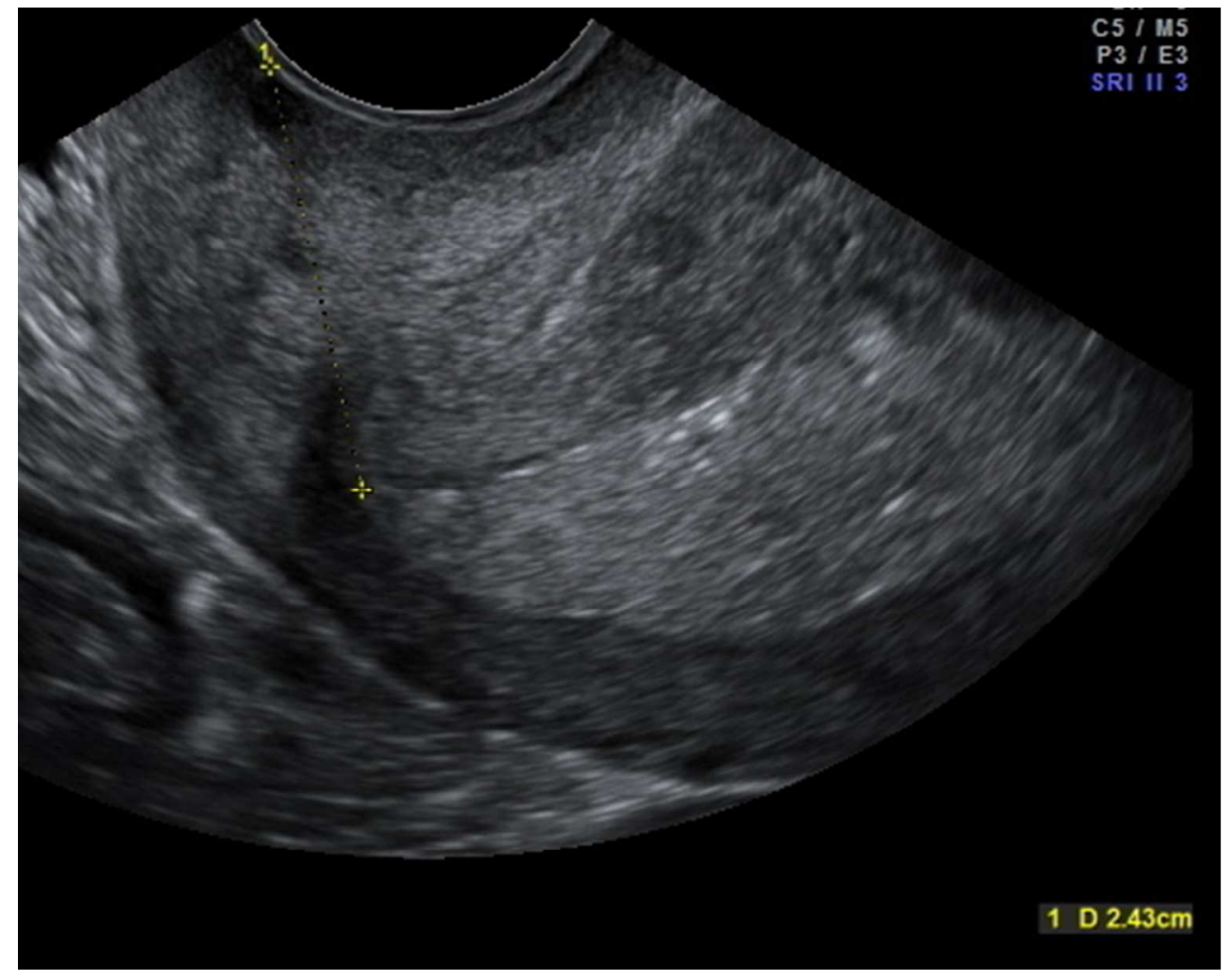

Figure 1. Endometrial tumor measurements; a/distance from outer cervical os to lower margin of the tumor in the sagital plane. 


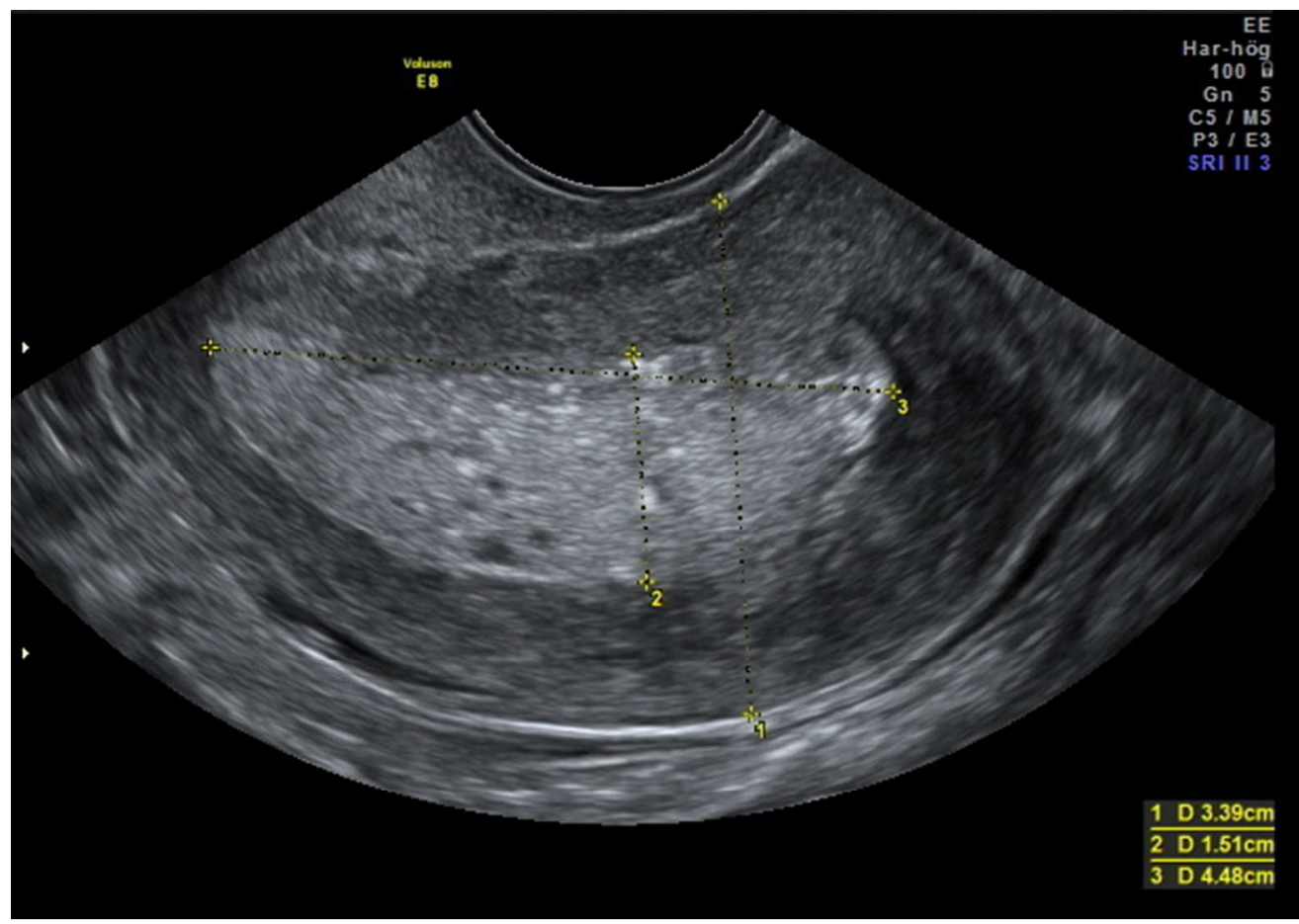

b/ anteroposterior diameter of the uterus, antero-posterior (tumor thickness) and cranio-caudal (tumor length) tumor diameters in the sagittal plane, 


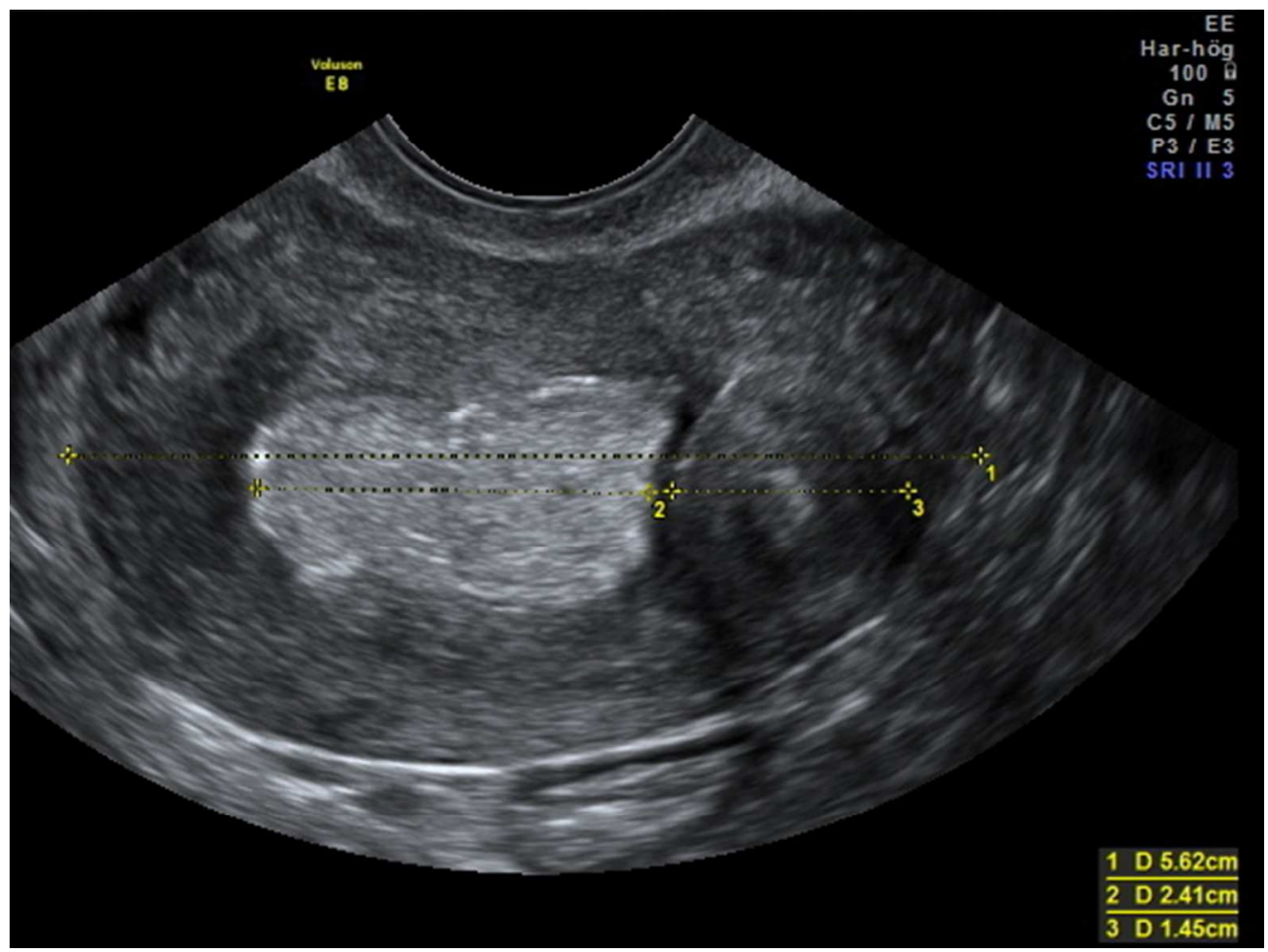

c/ latero-lateral diameter of the uterus (uterine width) and latero-lateral tumor diameter (tumor width) in the transverse plane, 


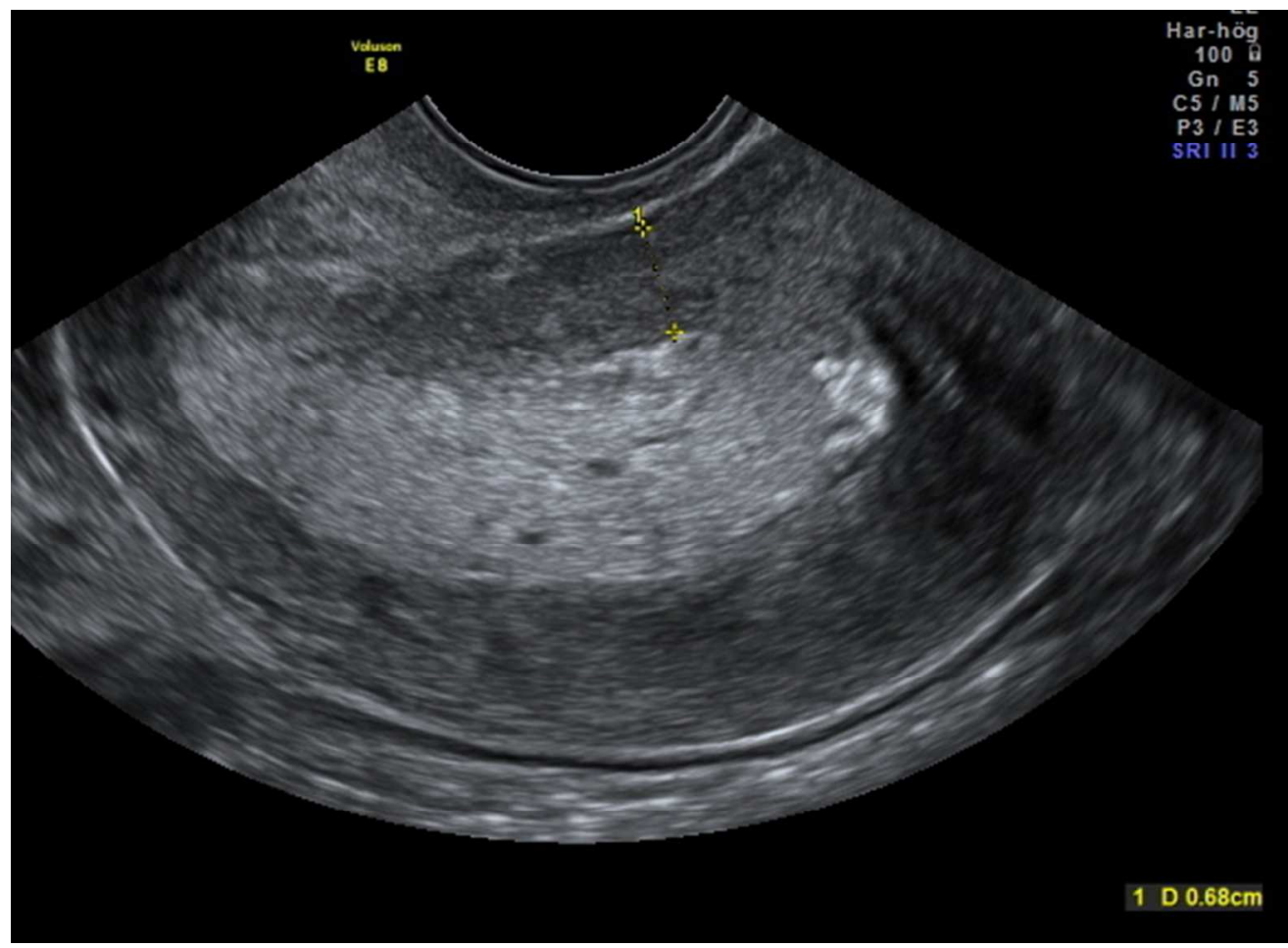

d/ minimal tumor-free margin measured in any plane where the distance from the tumor to the serosa appears to be at its the smallest. 


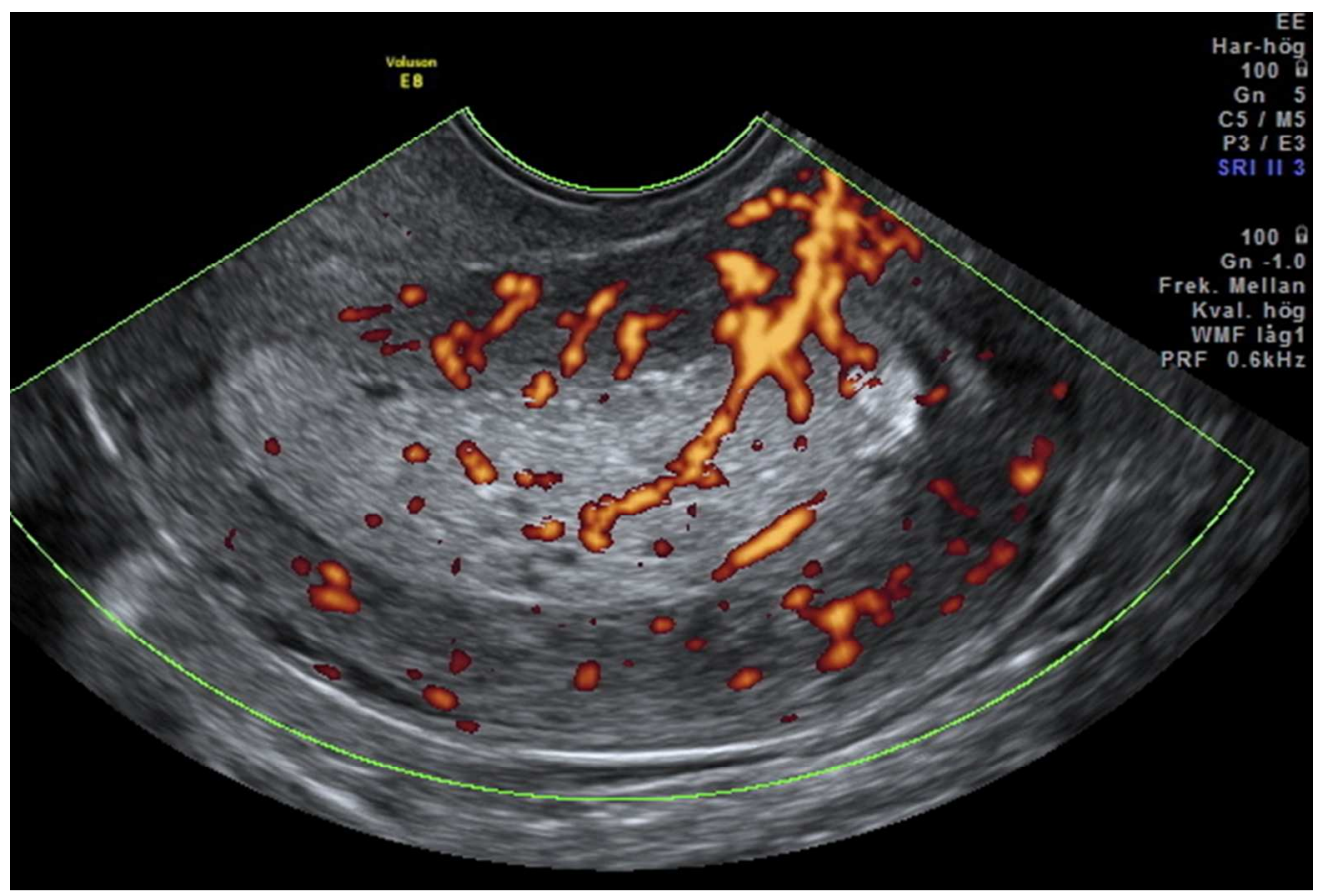

Figure 2. Ultrasound images of endometrioid tumors of different stage and grade; a/ stage IA, grade 


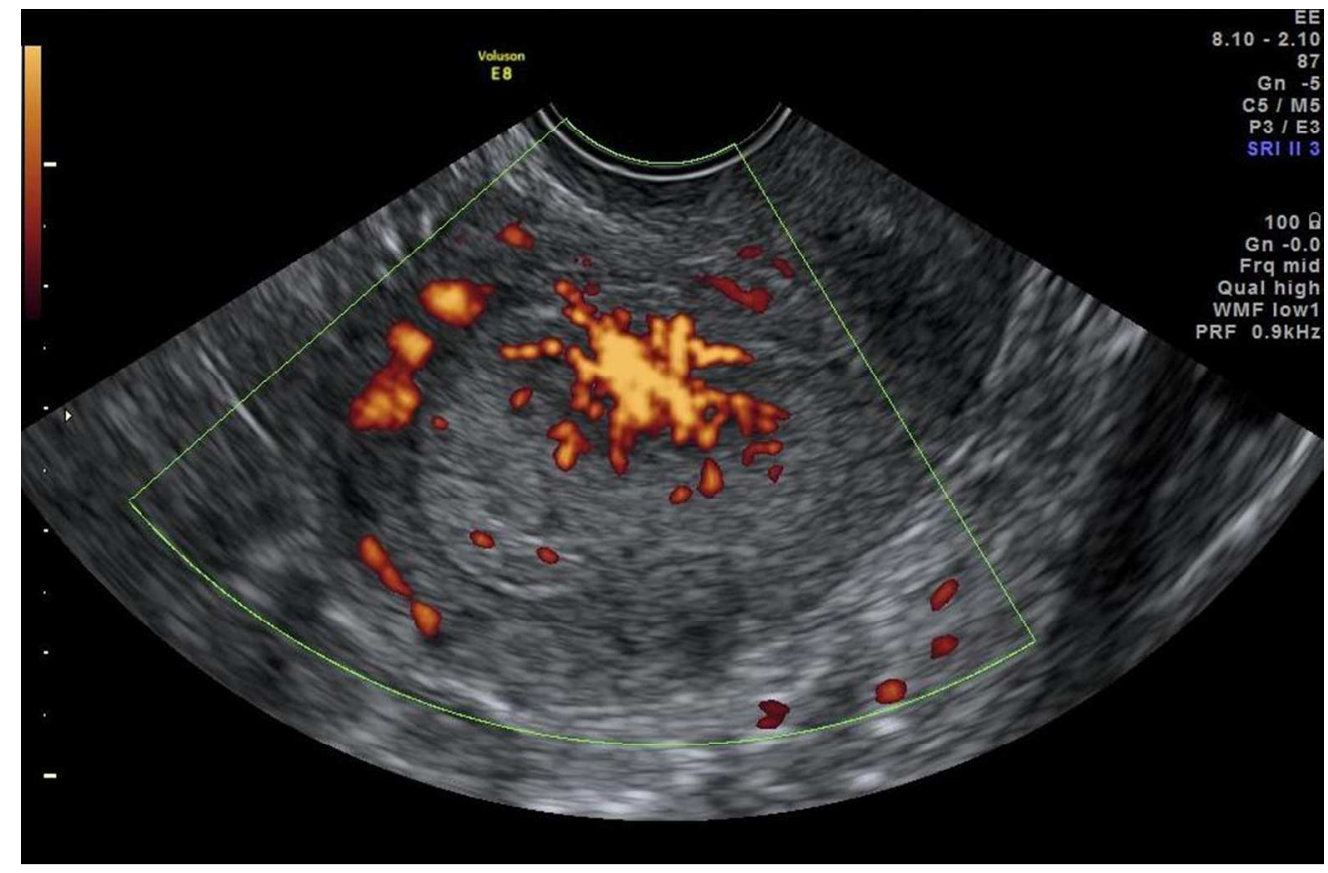

b/ stage IA, grade 2 


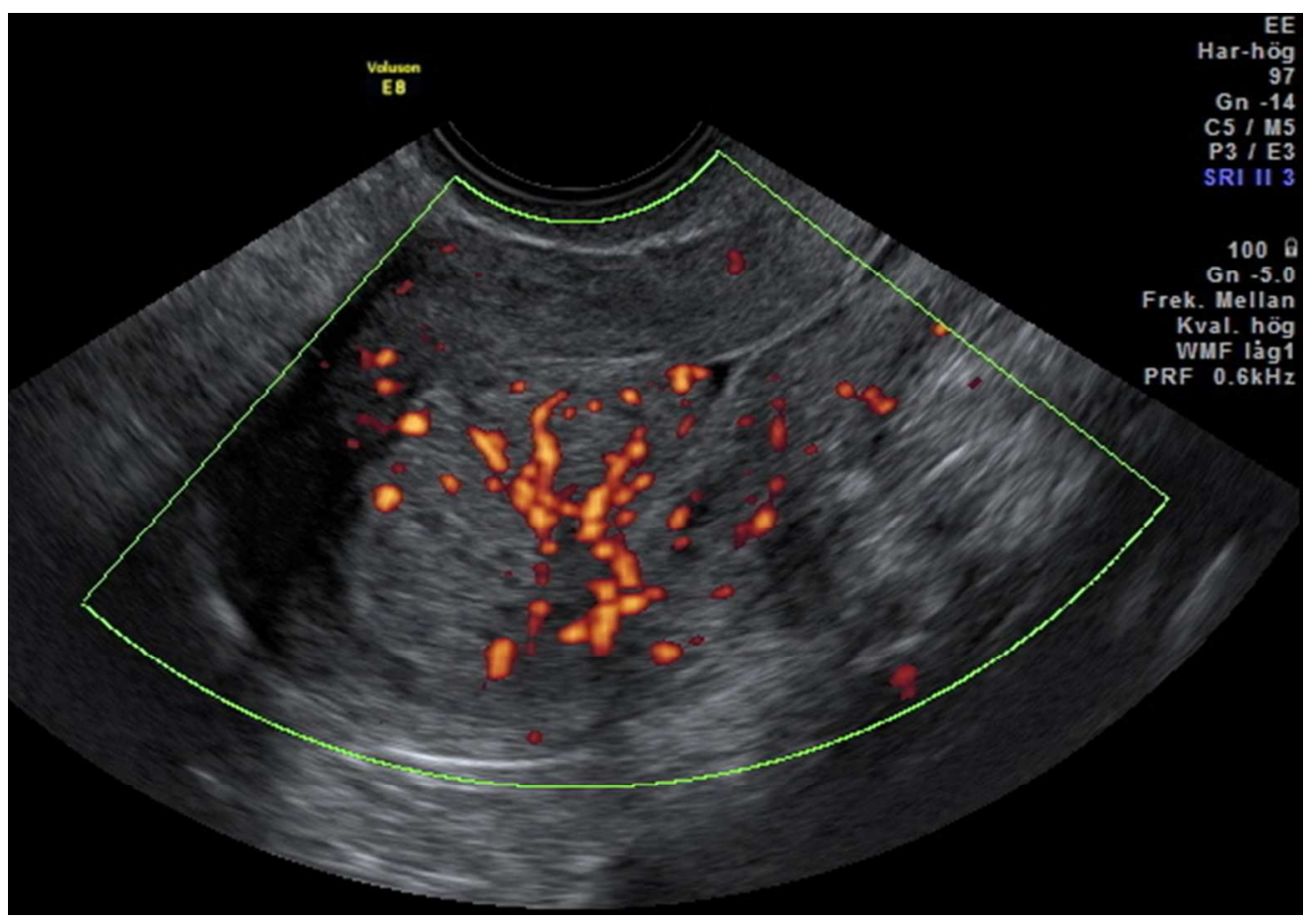

c/ stage $1 \mathrm{~A}$, grade 3 


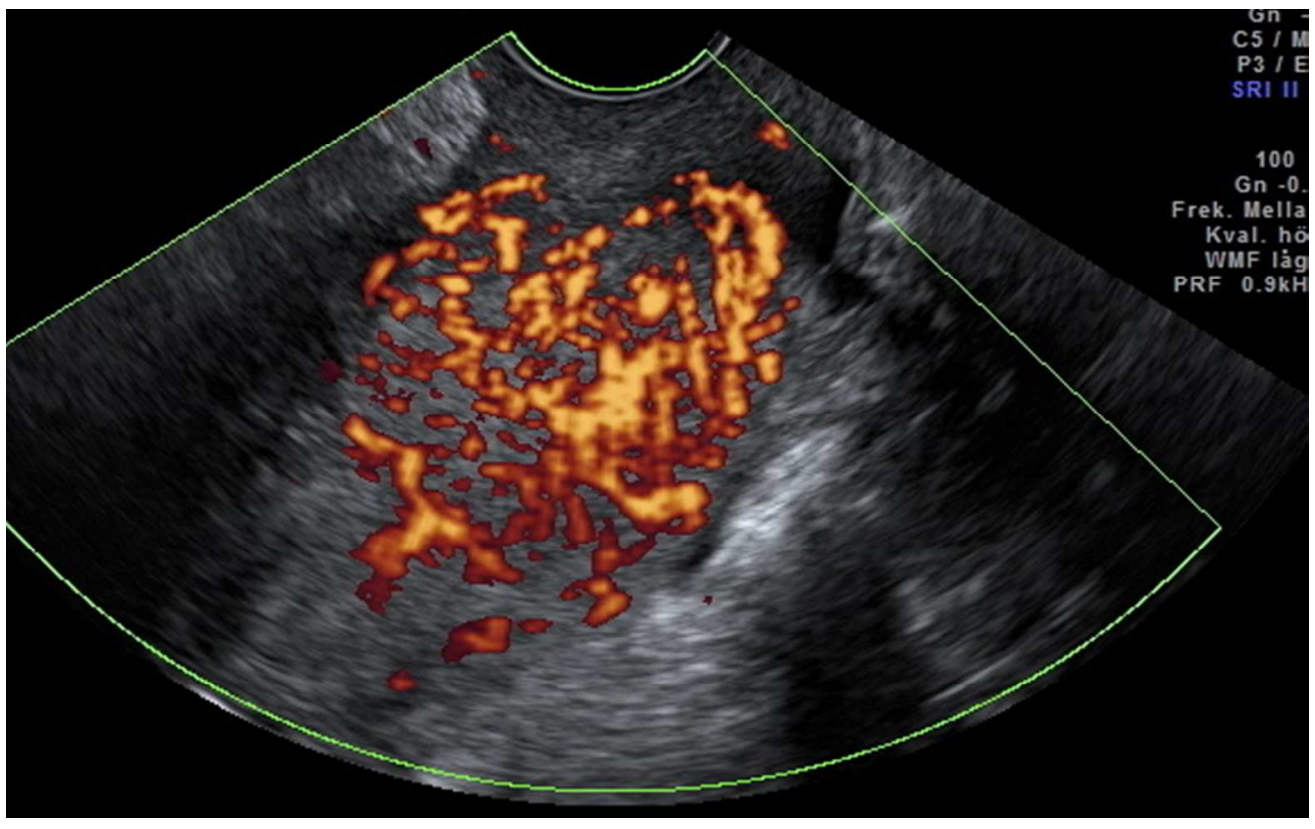

e/ stage II, grade 3

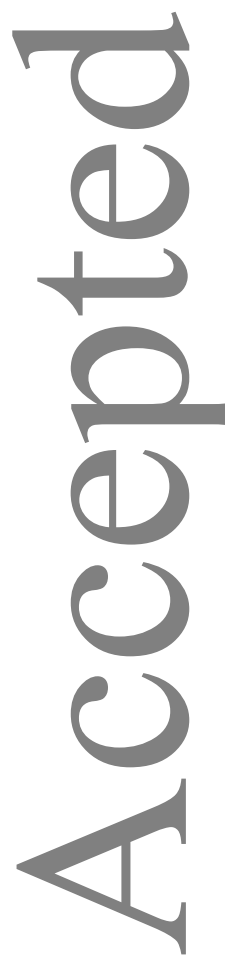




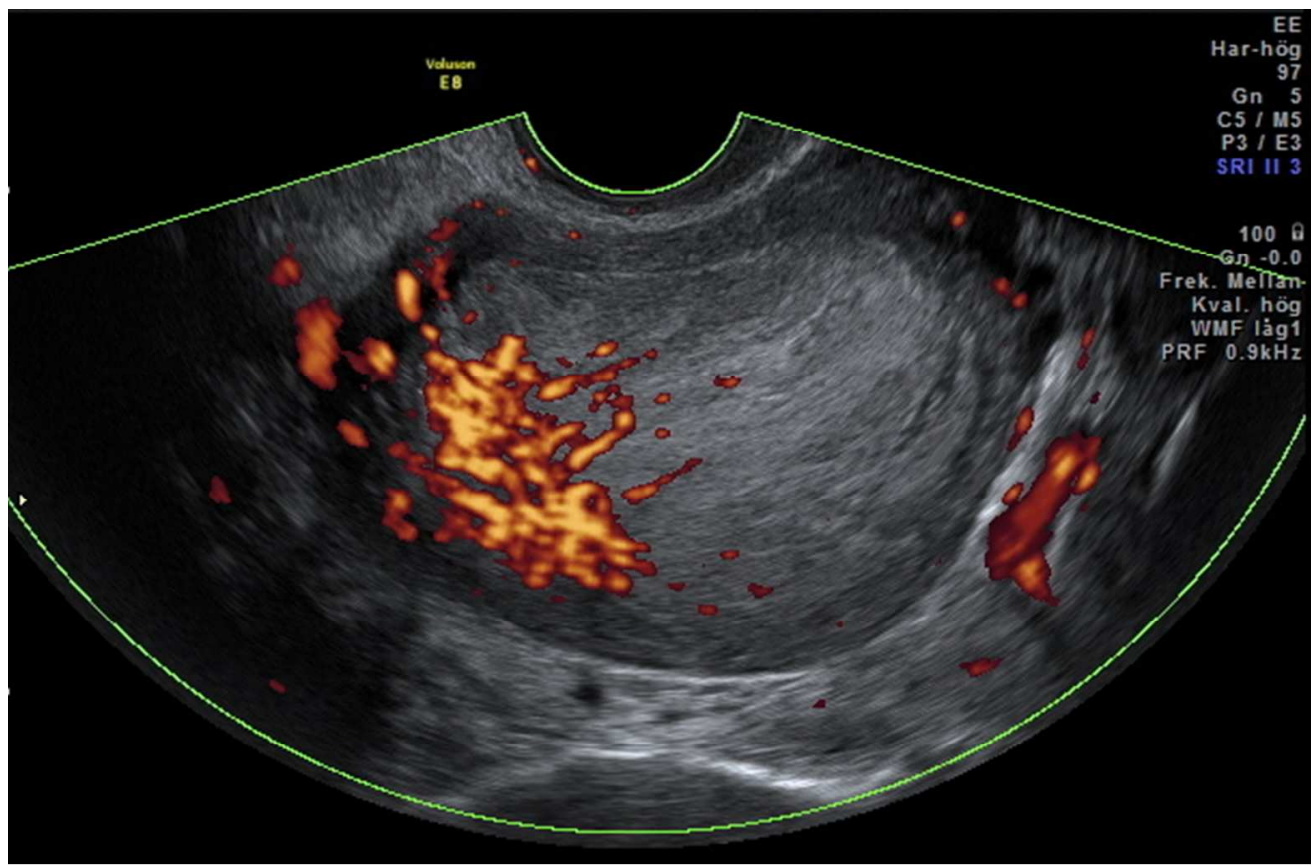

Figure 3. Ultrasound images of endometrial cancer of non-endometrioid histological type; a/ carcinosarcoma, stage IA 


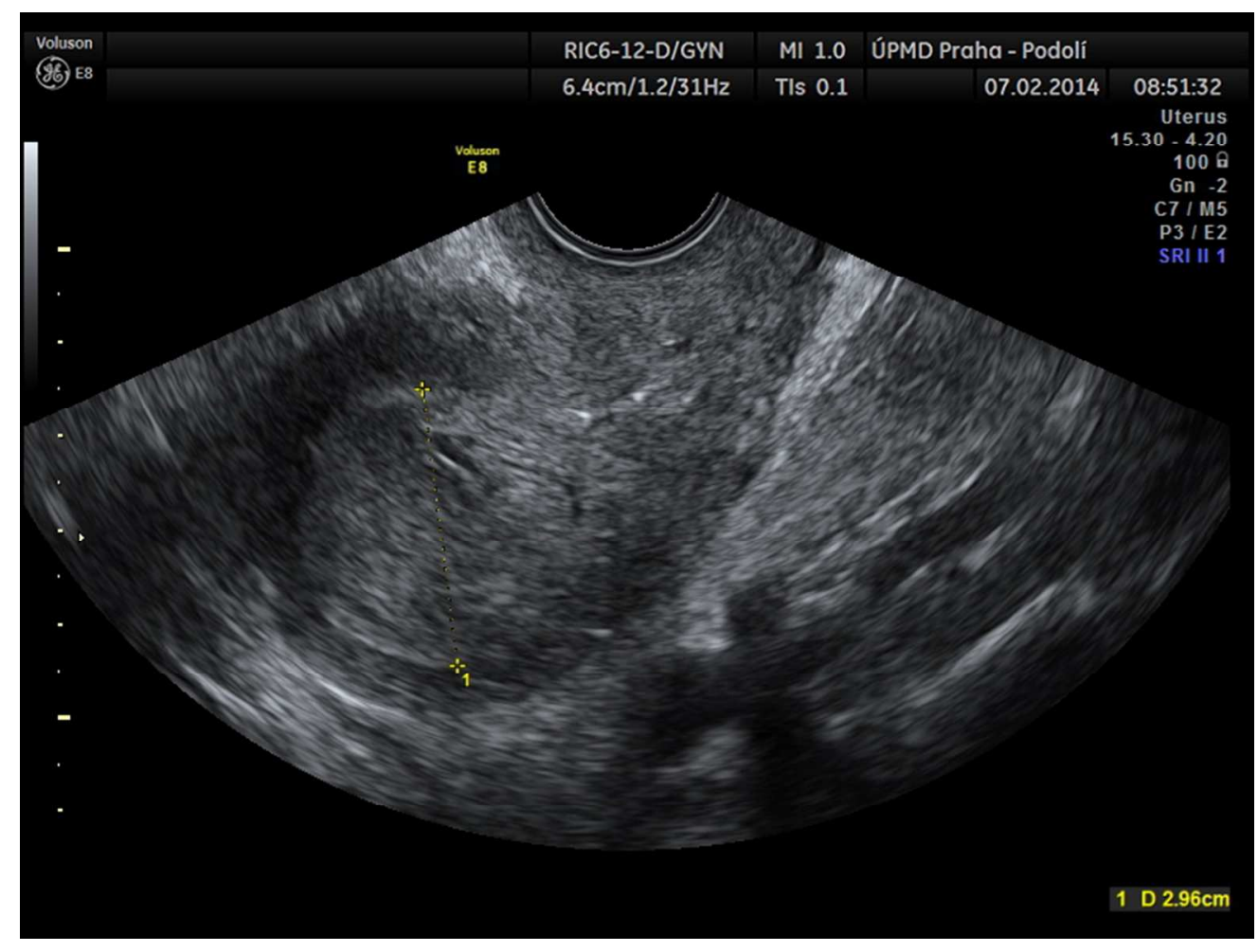

e/ clear cell carcinoma, stage IIIC 


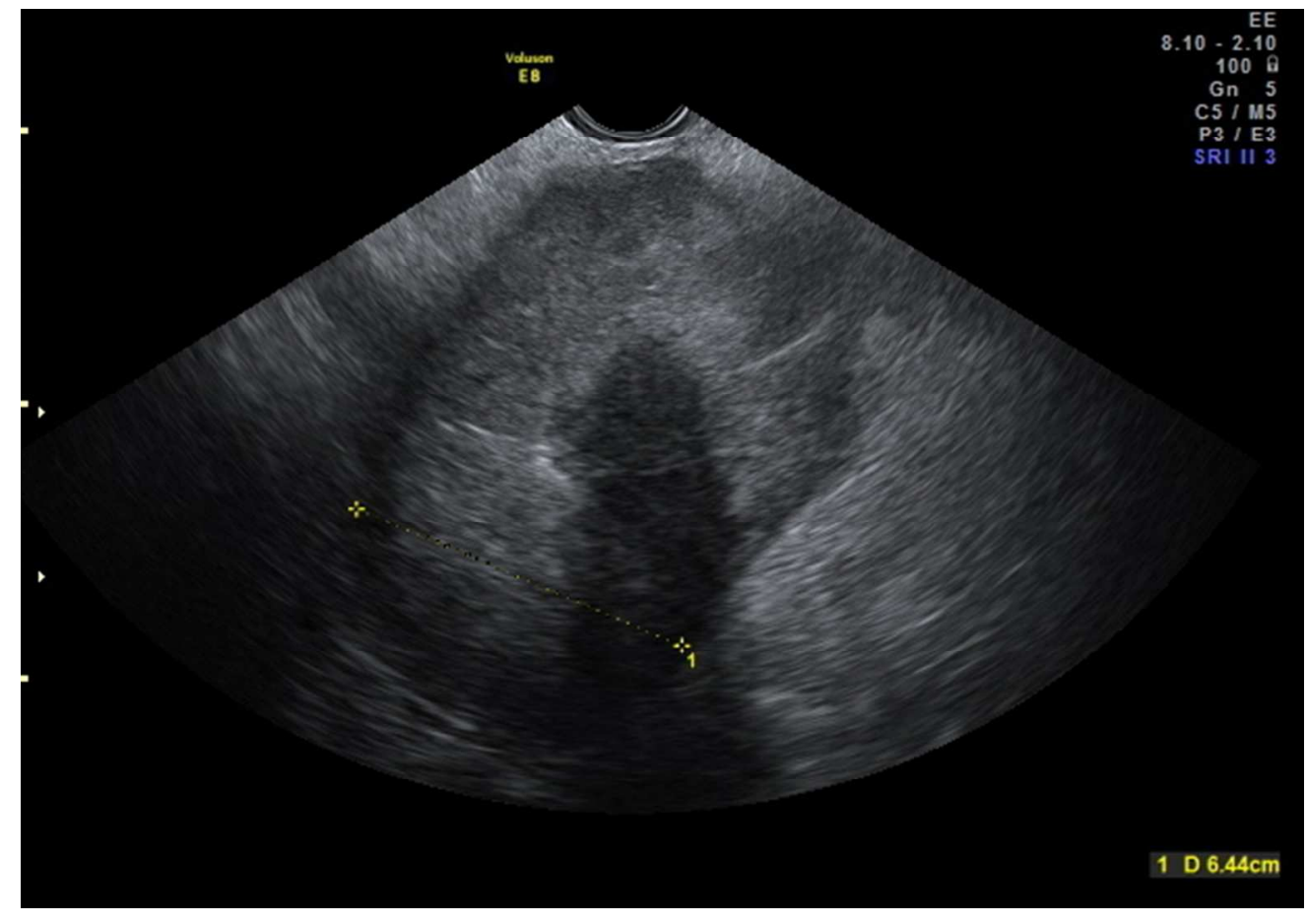

h/ mixed cell carcinoma, stage IIIC 